\title{
Model-Free Adaptive Nonlinear Control of the Absorption Refrigeration System
}

\section{Na Dong ( $\nabla$ dongna@tju.edu.cn )}

Tianjin University https://orcid.org/0000-0003-2982-3441

\section{Wenjin Lv}

Tianjin University

\section{Shuo Zhu}

Tianjin University

\section{Zhong-ke Gao}

Tianjin University

\section{Celso Grebogi}

University of Aberdeen

\section{Research Article}

Keywords: model-free adaptive control (MFAC), output error rate, absorption chiller

Posted Date: February 12th, 2021

DOI: https://doi.org/10.21203/rs.3.rs-180464/v1

License: (1) This work is licensed under a Creative Commons Attribution 4.0 International License. Read Full License

Version of Record: A version of this preprint was published at Nonlinear Dynamics on November 9th, 2021. See the published version at https://doi.org/10.1007/s11071-021-06964-5. 


\title{
Model-free adaptive nonlinear control of the absorption refrigeration system
}

\author{
Na Dong · Wenjin Lv · Shuo Zhu • Zhongke Gao • Celso Grebogi
}

Received: date / Accepted: date

\begin{abstract}
Based on the model-free adaptive control (MFAC) theory, the temperature tracking control problem of single-effect $\mathrm{LiBr} / \mathrm{H} 2 \mathrm{O}$ absorption chiller is explored. Due to the complex nonlinearity and strong coupling characteristics of the absorption refrigeration system, model-free adaptive control strategy is designed for its temperature tracking control. Nevertheless, the traditional model-free adaptive control has a slow tracking speed and poor denoising ability. In order to improve its control effect, output error rate is added to the objective function and new control laws of model-free adaptive control with output error rate (MFAC-OER) have been derived through an exhaustive convergence and stability analysis. The input and output information of the absorption refrigeration system, namely the hot water pump frequency and frozen water outlet water temperature, are combined. The data model of the absorption refrigeration system is subsequently deduced using a compact format dynamic linearization method.
\end{abstract}

\section{F. Na Dong}

School of Electrical and Information Engineering, Tianjin University, Tianjin 300072, China

S. Wenjin Lv

School of Electrical and Information Engineering, Tianjin University, Tianjin 300072, China

T. Shuo Zhu

School of Electrical and Information Engineering, Tianjin University, Tianjin 300072, China

F. Zhongke Gao ( ( )

School of Electrical and Information Engineering, Tianjin University, Tianjin 300072, China E-mail: zhongkegao@tju.edu.cn

F. Celso Grebogi

Institute for Complex Systems and Mathematical Biology, Kings College, University of Aberdeen, Aberdeen AB24 3UE, U.K
Next, based on the single effect absorption chiller experimental platform in our laboratory, its sixth-order dynamic model is built. Finally, the effectiveness and practicability of the improved control strategy are validated by numerical simulations and experimental operating data from our laboratory as well as by the dynamical model of the absorption chiller.

Keywords model-free adaptive control (MFAC) . output error rate $\cdot$ absorption chiller

\section{Introduction}

Absorption refrigeration systems (ARSs) [1] has attracted wide attention in recent years due to its features of environmental friendliness, energy saving and utilization of industrial waste heat. As the absorption refrigeration system has the characteristics of strong inertia, large time delay, high nonlinearity and strong coupling, its precise mathematical model is extremely hard to get. Many scholars have conducted research on the control of absorption refrigeration system. For example, Dewar and Didion optimized the control scheme through openloop control [2] and simple start-stop control [3]. Besides, some other researchers designed control schemes through closed-loop control strategies $[4,5]$. With the development of artificial intelligence, advanced control algorithms such as fuzzy control, artificial neural network, and genetic algorithm have been used in the control process of absorption refrigeration systems [6,7]. As the absorption refrigeration system has the characteristics of strong inertia, large time delay, high nonlinearity and strong coupling, those kind of model-based control methods are often difficult to achieve satisfactory control results. Therefore, this work utilizes the data-driven control technique to do the control design 
of the absorption refrigeration system, which is entirely based on the system input and output (I/O) data. Datadriven control refers to all control theories and methods in which the controller is designed by directly using the online or offline I/O data of the controlled system or knowledge from the data processing. But, no explicit information from the mathematical model of the control process, as in the cases of proportional integral derivative (PID) controller, model-free adaptive control (MFAC), and iterative learning control [8].

Although the most widely used PID control does not need to establish a mathematical model, it is more suitable for linear systems, and is not appropriate for systems which are strongly nonlinear, time-varying, and have strong coupling. It does not have the capability of learning and adapting to the structural changes of the system, thus causing worse control performance, with slow response, frequent overshooting, and other shortcomings [9-12]. MFAC is a control method that can realize nonlinear adaptive control with adaptive parameters as well as control structure. Compared with the traditional PID control algorithm, MFAC has stronger robustness and anti-interference ability. The MFAC method [13-15] is an effective data-driven control method for nonlinear control systems. In the past decade, MFAC has been widely studied and successfully applied in transportation, petroleum refining, chemical industry, and many other fields [16]. However, there is little research about MFAC in terms of the absorption refrigeration control system.

MFAC method has attracted much attention since it was proposed. However, the tracking speed of MFAC needs to be further improved. Aiming at this, this work proposes an improved control based law for MFAC method. In order to improve the tracking speed, the proposed method not only utilizes the output error, but also introduces the output error rate in our new MFAC-OER control. The two terms are fused and weighted to eliminate the influence of the output error.

The main contributions of this work are highlighted as follows:

\section{Model-Free Adaptive Control}

At each key stage, the equivalent dynamic linearized data model of the nonlinear system is established, and the pseudo-partial derivatives (PPD) [13] of the system is estimated online by the $\mathrm{I} / \mathrm{O}$ data of the controlled system.

\section{Model-Free Adaptive Control with Output Error Rate}

A new control law based on MFAC method is proposed in this work. In order to shorten the tracking time, the output error rate is introduced into the control input criterion function. Furthermore, the improved MFACOER control law is obtained.

\section{Sixth-order Dynamic Model of Absorption}

\section{Refrigeration System}

Based on the single effect absorption chiller experimental platform in our laboratory, a simplified sixthorder dynamic model that satisfies the demand for control system design and optimization is obtained and validated through experimental operating data of the unit.

The remaining of the paper is organized as follows. The basic MFAC theory is introduced in Section 2. The improved MFAC-OER based on output error rate is developed in Section 3, including the complete convergence and stability analysis is given. In Section 4, the effectiveness of the proposed approach is validated by numerical simulation as well as the dynamical model of the absorption chiller.

\section{Preliminaries on Model-free Adaptive Control (MFAC)}

Firstly, we give a brief review of the MFAC approach [15]. The main advantage of the MFAC algorithm is that it does not use the mathematical model of the process in the controller design, but uses only its input/output data. The MFAC algorithm guarantees the stability of the control system structure by fulfilling a reset mechanism.

\subsection{Dynamic linearization}

We consider the following general discrete time system [17]:

$y(k+1)=f\left(y(k), y(k-1), \ldots, y\left(k-n_{y}\right), u(k)\right.$, $\left.u(k-1), \ldots, u\left(k-n_{u}\right)\right)$,

where, $y(k)$ and $u(k)$ are the output and input of the system, respectively. $n_{y}$ and $n_{u}$ are the orders of the system output and input, respectively. $f(\ldots)$ is the output as a function of the input.

Hypothesis 1: (1) is an observable and controllable system. That is, the desired output signal $y^{*}(k)$ is bounded by the external perturbations, and there exists a bounded and feasible control input to drive the output to the desired state.

Hypothesis 2: $f(\ldots)$ 's partial derivative of the current control input signal $u(k)$ is continuous [18].

Hypothesis 3: The system satisfies the generalized Lipschitz condition [19], which is: for any $k$ and $u(k)=$ 0 , there is $b>0$ satisfying $|\Delta y(k+1)| \leq b|\Delta u(k)|$, 
where, $\Delta y(k+1)=y(k+1)-y(k), \Delta u(k)=u(k)-$ $u(k-1)$, and $b$ is a constant.

Theorem: For equation (1), if the hypotheses 1-3 are satisfied, then, when $\Delta u \neq 0$, there must be a pseudopartial-derivative $\phi(k)$, so that:

$\Delta y(k+1)=\phi(k) \Delta u(k)$,

where $|\phi(k)| \leq b . b$ is a constant and (2) is the general model of (1).

\subsection{Control law}

In order to make equation (2) accurate and reasonable, we replace equation (1) to limit the variation of $u(k)$. The change of $u(k)$ is constrained by adding variable parameters to the control algorithm [20]. So we introduce the control input criteria function as:

$J(u(k))=$

$\left|y^{*}(k+1)-y(k+1)\right|^{2}+\lambda|u(k)-u(k-1)|^{2}$,

where, $\lambda$ is the weight factor and $y^{*}(k)$ is the desired output signal. The second term $\lambda|u(k)-u(k-1)|^{2}$ in the formula is to limit the change of $u(k)$. It has the ability to overcome the steady-state tracking error.

Substitute equation (2) into equation (3), take the derivative and set it to zero:

$\frac{\partial J(u(k))}{\partial u(k)}=0$.

Then:

$u(k)=u(k-1)+\frac{\rho \phi(k)}{\lambda+|\phi(k)|^{2}}\left[y^{*}(k+1)-y(k)\right]$,

where, $\rho$ is the step length. Formula (5) is used to calculate the control law of MFAC. From the above modelfree adaptive control scheme, it can be seen that the control law is based only on the input and output data of the system. Only one parameter needs to be adjusted online: the pseudo partial derivative $\phi(k)$.

As the pseudo-partial derivative estimation (PPD) of the system is unknown, we replace $\phi(k)$ with $\hat{\phi}(k)$, which are the online estimation of $\phi(k)$, the control law changes to:

$u(k)=u(k-1)+\frac{\rho \hat{\phi}(k)}{\lambda+|\hat{\phi}(k)|^{2}}\left[y^{*}(k+1)-y(k)\right]$,

which is at the core of our work.

2.3 Pseudo-partial derivative estimation (PPD) algorithm

The pseudo-partial derivative estimation algorithm [21] uses the following estimation criterion function:

$$
\begin{gathered}
J(\phi(k))=|y(k)-y(k-1)-\phi(k) \Delta u(k-1)|^{2}+ \\
\mu|\phi(k)-\hat{\phi}(k-1)|^{2}
\end{gathered}
$$

where $y(k)$ is the true output of the system. Due to the introduction of $\mu|\phi(k)-\hat{\phi}(k-1)|^{2}$, the variation of the time varying parameter $\phi(k)$ can be limited effectively. Through a lengthy derivation, we can get the estimation of $\phi(k)[20]$, written as follows:

$$
\begin{aligned}
& \hat{\phi}(k)=\hat{\phi}(k-1) \\
& +\frac{\eta \Delta u(k-1)}{\mu+|\Delta u(k-1)|^{2}} \times(\Delta y(k)-\hat{\phi}(k-1) \Delta u(k-1)),
\end{aligned}
$$

where $\mu$ is the weight factor and $\eta$ is the step length.

\section{Model-free Adaptive Control design with output error rate (MFAC-OER)}

To improve the slow tracking speed and the poor denoising ability of the traditional model-free adaptive control strategy, output error rate is added to the objective function and new control laws, MFAC-OER, have been derived with comprehensive convergence and stability analyses.

\subsection{Improved control strategy}

In order to reduce the tracking time, we propose the following calculation criteria based on equation (3):

$J(u(k))=\theta e(k+1)^{2}+(1-\theta)\left[\frac{|e(k+1)|-|e(k)|}{T}\right]^{2}+$ $\lambda|u(k)-u(k-1)|^{2}$,

where, $e(k)=y^{*}(k)-y(k)$ is the output error, $y^{*}(k)$ is a given signal, and $y(k)$ is the output signal. $\theta$ is the weight coefficient, which is used to balance the importance between output error and output error rate.

Equation (9) limits the effect of large errors in the calculation of the control law by introducing $\left[\frac{|e(k+1)|-|e(k)|}{T}\right]^{2}$. The control law can be optimized by adjusting $\theta$. Furthermore, the system can now reach a steady state faster.

Substituting equation (2) into equation (7) and using equation (4), we get:

$\Delta u(k)=$
$\frac{\left(y^{*}(k+1)-y(k)\right)\left(\theta+\frac{1-\theta}{T^{2}}\right) \hat{\phi}(k)-\hat{\phi}(k) \frac{1-\theta}{T^{2}} e(k)}{\lambda+\hat{\phi}^{2}(k)+\hat{\phi}^{2}(k) \frac{1-\theta}{T^{2}}}$.

Therefore, the proposed MFAC algorithm, combining with the output error rate (MFAC-OER), can be described as:

$\Delta u(k)=$

$\frac{\left(y^{*}(k+1)-y(k)\right)\left(\theta+\frac{1-\theta}{T^{2}}\right) \hat{\phi}(k)-\hat{\phi}(k) \frac{1-\theta}{T^{2}} e(k)}{\lambda+\hat{\phi}^{2}(k)+\hat{\phi}^{2}(k) \frac{1-\theta}{T^{2}}}$,

where

$\hat{\phi}(k)=\hat{\phi}(k-1)+\frac{\eta \Delta u(k-1)}{\mu+|\Delta u(k-1)|^{2}} \times(\Delta y(k)-$

$\hat{\phi}(k-1) \Delta u(k-1))$. 
The control block diagram is given in Fig. 1. As can be seen, the PPD estimation of $\phi(k)$ is the input in the control law formula to get the control $u(k)$. Then, the control signal is fed back to the controlled system to complete the entire system control.

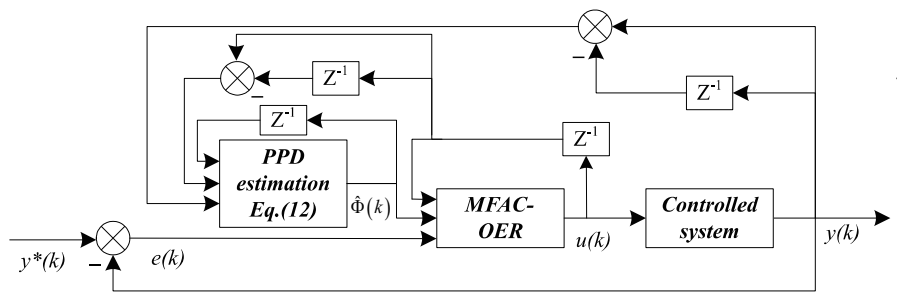

Fig.1 The control block diagram

\subsection{Stability analysis}

The proof of the convergence of $\phi(k)$ is shown in [21]. Next, we prove the stability and convergence of $y(k)$ and $u(k)$. For the convenience of the proof, we make the following definition: $l_{1}=\theta+\frac{1-\theta}{T^{2}}, l_{2}=\frac{1-\theta}{T^{2}}$, where, $l_{1}>l_{2}$ and $l_{1}$ and $l_{2}$ are positive variables. In order to make the proof rigorous, the following hypothesis [22] is given.

Hypothesis 4: For any $k$ step, when $\Delta u \neq 0$, the sign of PPD stays the same, and it satisfies the condition $\phi(k)>\xi>0$, where $\xi$ is a small positive real number. Firstly, we prove the convergence of $y(k)$,

$$
\begin{aligned}
& \left|y^{*}-y(k+1)\right|=\left|y^{*}-y(k)-\phi(k) \Delta u(k)\right| \\
& =\left|y^{*}-y(k)-\frac{\left(l_{1}-l_{2}\right) \hat{\phi}(k) \phi(k)\left(y^{*}-y(k)\right)}{\lambda+\left(1+l_{2}\right) \hat{\phi}^{2}(k)}\right| \\
& =\mid \begin{array}{l}
\left(y^{*}-y(k)\right)\left(1-\frac{\left(l_{1}-l_{2}\right) \hat{\phi}(k) \phi(k)}{\lambda+\left(1+l_{2}\right) \hat{\phi}^{2}(k)}\right) \mid \\
\leq \mid 1-\frac{\left(l_{1}-l_{2}\right) \hat{\phi}(k) \phi(k)}{\lambda+\left(1+l_{2}\right) \hat{\phi}^{2}(k)} \|\left(y^{*}-y(k) \mid .\right.
\end{array}
\end{aligned}
$$

Let $e(k+1)=y^{*}-y(k+1)$, equation (13) can be expressed as:

$|e(k+1)| \leq\left|1-\frac{\left(l_{1}-l_{2}\right) \hat{\phi}(k) \phi(k)}{\lambda+\left(1+l_{2}\right) \hat{\phi}^{2}(k)}\right||e(k)|$.

Choosing $\lambda_{\min }=\frac{b^{2}\left(l_{1}-l_{2}\right)^{2}}{4\left(1+l_{2}\right)}$ and using the inequality $\lambda+\left(1+l_{2}\right) \hat{\phi}^{2}(k) \geq 2 \sqrt{\lambda\left(1+l_{2}\right)} \hat{\phi}(k)$, there exists a constant $M$ that makes the following statement true:

$$
\begin{aligned}
& 0<M \leq \frac{\left(l_{1}-l_{2}\right) \hat{\phi}(k) \phi(k)}{\lambda+\left(1+l_{2}\right) \hat{\phi}^{2}(k)} \leq \frac{b\left(l_{1}-l_{2}\right) \hat{\phi}(k)}{\lambda+\left(1+l_{2}\right) \hat{\phi}^{2}(k)} \\
& \leq \frac{b\left(l_{1}-l_{2}\right) \hat{\phi}(k)}{2 \sqrt{\lambda\left(1+l_{2}\right)} \hat{\phi}(k)}<\frac{b\left(l_{1}-l_{2}\right)}{2 \sqrt{\lambda_{\min }\left(1+l_{2}\right)}}=1 .
\end{aligned}
$$

According to (15) and $\lambda>\lambda_{\min }$, we get:

$$
\begin{aligned}
& \left|1-\frac{\hat{\phi}(k) \phi(k)}{\lambda+\left(1+l_{2}\right) \hat{\phi}^{2}(k)}\right|=1-\frac{\hat{\phi}(k) \phi(k)}{\lambda+\left(1+l_{2}\right) \hat{\phi}^{2}(k)} \\
& \leq 1-M=<1 .
\end{aligned}
$$

By combine equations (14) and (16), there is a constant $\mathrm{c}$ that makes the following statement true:

$|e(k+1)| \leq c|e(k)| \leq c^{2}|e(k-1)| \leq \ldots \leq c^{k}|e(1)|$.

From $(17), y(k)$ is convergent. Next, we prove the convergence of $u(k)$ :

Using $\lambda+\left(1+l_{2}\right) \hat{\phi}^{2}(k) \geq 2 \sqrt{\lambda\left(1+l_{2}\right)} \hat{\phi}(k)$ and $\lambda>$ $\lambda_{\text {min }}$, from equation (10), we have:

$$
\begin{gathered}
|\Delta u(k)|=\left|\frac{\left(l_{1}-l_{2}\right) \hat{\phi}(k) e(k)}{\lambda+\left(1+l_{2}\right) \hat{\phi}^{2}(k)}\right| \leq\left|\frac{\left(l_{1}-l_{2}\right) \hat{\phi}(k)}{\lambda+\left(1+l_{2}\right) \hat{\phi}^{2}(k)}\right||e(k)| \\
\leq\left|\frac{\left(l_{1}-l_{2}\right) \hat{\phi}(k)}{2 \sqrt{\lambda\left(1+l_{2}\right)} \hat{\phi}(k)}\right||e(k)| \leq\left|\frac{\left(l_{1}-l_{2}\right)}{2 \sqrt{\lambda_{\min }\left(1+l_{2}\right)}}\right||e(k)| \\
=M_{1}|e(k)|,
\end{gathered}
$$

where, $M_{1}=\frac{\left(l_{1}-l_{2}\right)}{2 \sqrt{\lambda_{\min }\left(1+l_{2}\right)}}$ is a bounded constant.

According to (17) and (18), we have:

$$
\begin{aligned}
& |u(k)| \leq|u(k)-u(k-1)|+|u(k-1)| \\
& \leq|u(k)-u(k-1)|+u(k-1)-u(k-2)|+| u(k-2) \mid \\
& \leq|\Delta u(k)|+|\Delta u(k-1)|+\ldots+|\Delta u(2)|+|u(1)| \\
& \leq M_{1}(|e(k)|+|e(k-1)|+\ldots+|e(2)|)+|u(1)| \\
& \leq M_{1}\left(l^{k-1}|e(1)|+l^{k-2}|e(1)|+\ldots+l|e(1)|\right)+|u(1)| \\
& \leq M_{1} \frac{l}{1-l}|e(1)|+|u(1)| .
\end{aligned}
$$

So, $u(k)$ is convergent. The proof is complete.

\section{Simulation and Discussion}

In this Section, the proposed algorithm is firstly validated by numerical simulations, and then it is applied to the control of absorption chiller.

\subsection{Numerical simulations}

\section{A.The influence of the weight $\theta$ on the tracking speed}

A typical plant is selected to illustrate the influence of the weight $\theta$ on the tracking speed of the MFAC-OER method, which can be described as:

$y(k+1)=0.905 \cdot y(k)+0.095 \cdot u(k)$.

The given signal is $y^{*}=1$. Parameters of the MFAC and the MFAC-OER algorithm, are fixed as: $\eta=0.1$, $\mu=0.1, \rho=1$ and $\lambda=65 . \theta$ in MFAC-OER is selected as $0.2 / 0.5 / 0.9$ respectively. The corresponding performances are given in Fig. 2.

Figure 2(a) shows that when the value of $\theta$ is 0.2 , the tracking speed of the MFAC-OER is not as good as the original MFAC method. As the value of $\theta$ gradually increases, the tracking speed of the MFAC-OER is improved. In Fig. 2(b), the MFAC-OER and MFAC method almost maintain the same tracking speed when the value is 0.5 . As can be noted in Fig. 2(c), for $\theta=0.9$, 
the tracking speed of the MFAC-OER is better than that of the original MFAC method. The simulations indicate that the output error rate $\theta$ plays an important role. Through the three comparison results in Fig. 2, it can be concluded that the output error rate has relevant impact on the optimization of the control law.

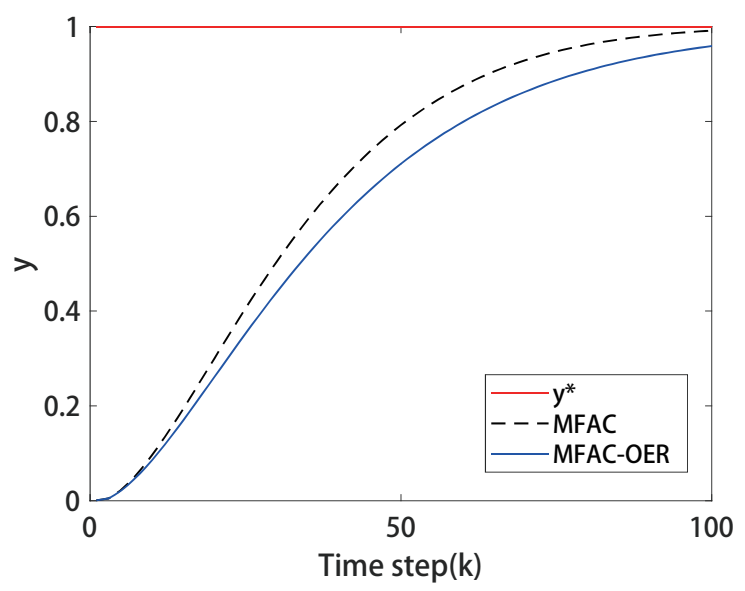

(a) Tracking comparison when $\theta=0.2$

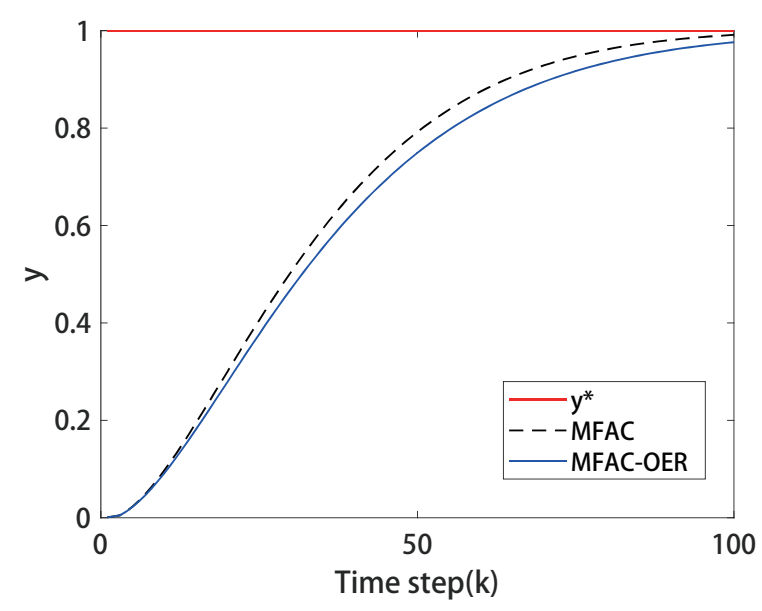

(b) Tracking comparison when $\theta=0.5$

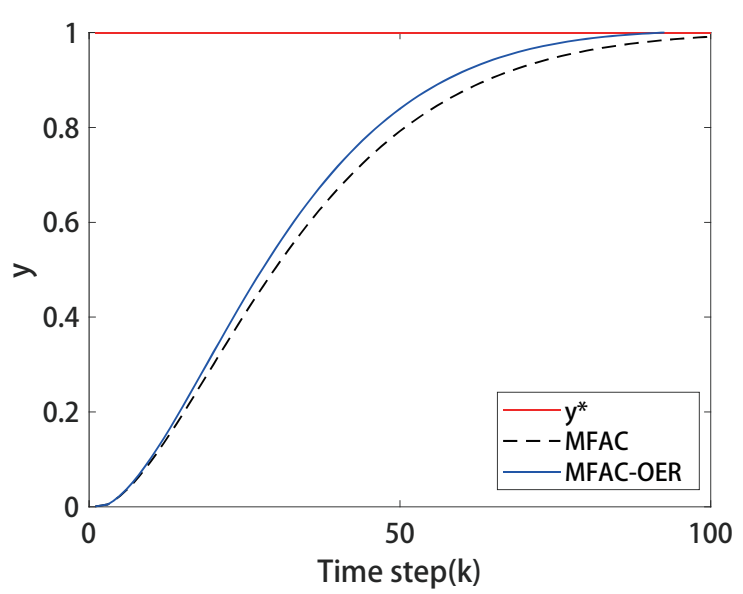

(c) Tracking comparison when $\theta=0.9$

Fig. 2. Tracking comparison of $\theta$ under different values

\section{B.The system simulation with time-varying sig- nals}

In order to validate the performance of the proposed algorithm in nonlinear tracking problems, a typical nonlinear plant is selected, and the comparative simulation of the MFAC and MFAC-OER algorithms are given under time-varying signals in Fig. 3.

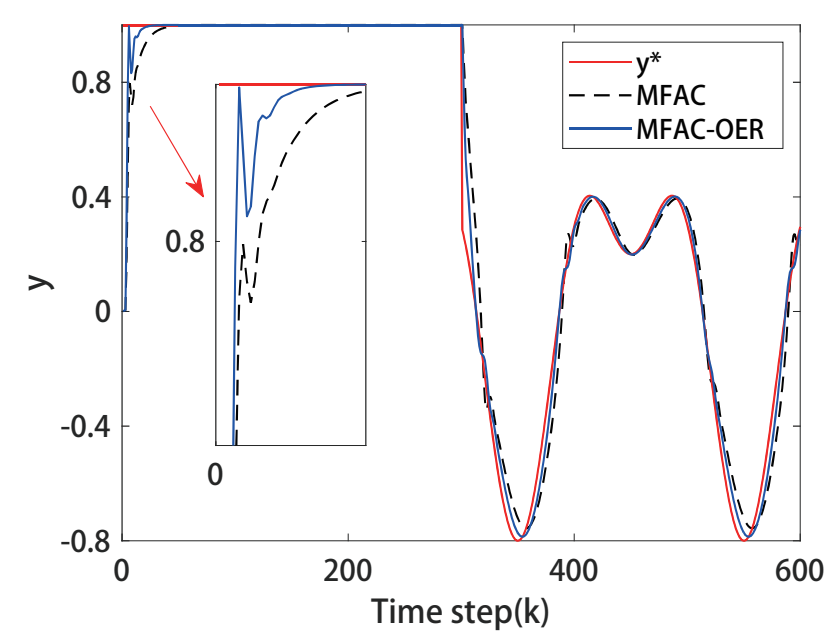

Fig. 3 Output comparison

We validate the effectiveness of the proposed MFACOER algorithm by using the following nonlinear system:

$$
\begin{aligned}
& y(k+1)= \\
& \frac{y(k)}{1+y^{2}(k)+y^{2}(k-1)+y^{2}(k-2)}+u(k) .
\end{aligned}
$$

The given signal is the following:

$$
\left\{\begin{array}{l}
y^{*}=1, k \leq 300 \\
y^{*}=0.5 \sin (\pi k / 100)+0.3 \cos (\pi k / 50), k>300
\end{array}\right.
$$

It is a step signal before the 300th step, and then it fluctuates in a manner similar to a sinusoidal signal after $k>300$.

Parameters of the MFAC and the MFAC-OER algorithms are selected as: $\eta=0.1, \mu=0.1, \rho=1, \lambda=3$. $\theta$ is fixed as 0.9 .

Table 1 shows the output error correlation indexes of the MFAC method and the MFAC-OER method.

Table 1 Error comparison of MFAC and MFAC-OER

\begin{tabular}{l|cc}
\hline \hline & MFAC & MFAC-OER \\
\hline MAE & 0.0151 & 0.0044 \\
\hline MSE & 0.0019 & 0.0003 \\
\hline
\end{tabular}

Note: MAE [23] is the mean absolute error: $\frac{1}{k} \sum_{i=1}^{k}\left|y_{i}-y_{i}^{*}\right|$, MSE is the mean square error: $\frac{1}{k} \sum_{i=1}^{k}\left(y_{i}-y_{i}^{*}\right)^{2}$. 
As can be seen from Fig. 3 and the error-related indicators in Table 1, for varying signals, the tracking effect of the proposed MFAC-OER method is superior to the original MFAC method. MAE and MSE obtained by the MFAC-OER are 4 times and 6 times smaller, respectly, than that of the original MFAC. The superiority of our proposed MFAC-OER is more obvious after the 300 th step.

\section{The system simulation with variable system}

In order to validate the control performance of the proposed MFAC-OER algorithm in dealing with system changes, a different nonlinear system [24] is taken, and comparative simulation experimental results are obtained as shown in Fig. 4.

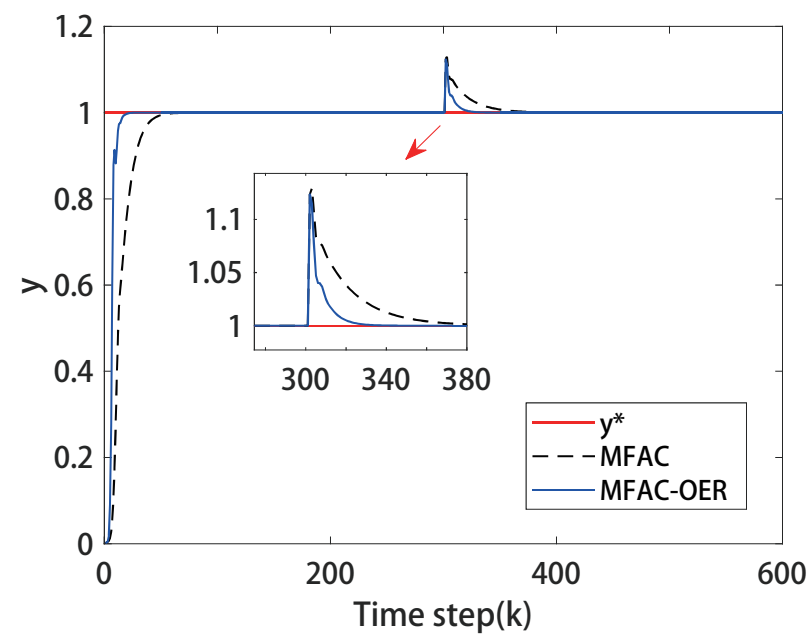

Fig.4 Output comparison

The controlled plant is given as follows:

$\left\{\begin{array}{l}y(k+1)=\frac{y(k)}{1+y^{2}(k)+y^{2}(k-1)}+u^{3}(k), k \leq 300 \\ y(k+1)=\frac{y(k)}{1+y^{2}(k)+y^{2}(k-1)+y^{2}(k-2)}+u(k), k>300\end{array}\right.$

As can be seen from Eq. (23), the controlled system has a change in the 300th step.

Consider the signal: $y^{*}=1$. Parameters of the MFAC and the MFAC-OER algorithms are fixed as: $\eta=0.1$, $\mu=0.1, \rho=1$, and $\lambda=15$. The value of $\theta$ is also set to 0.9 .

Table 2 shows the output error correlation indexes of the MFAC method and the MFAC-OER method.

Table 2 Error comparison of MFAC and MFAC-OER

\begin{tabular}{l|cc}
\hline \hline & MFAC & MFAC-OER \\
\hline MAE & 0.0147 & 0.0088 \\
\hline MSE & 0.0086 & 0.0056 \\
\hline
\end{tabular}

As can be seen from Fig. 4 and the error-related indicators in Table 2, MAE and MSE of the MFAC method are higher than that of the MFAC-OER method. Initially, as well as at the changing point at the 300th step, the MFAC-OER reaches a steady state much faster than the original MFAC, which indicates its advantage of dealing with sudden changes of the controlled system. According to the above results, it can be concluded that the proposed MFAC-OER method is superior to the original MFAC in tracking control problems. Meanwhile, it is faster and easier to reach a stable state.

\subsection{Physical experiment}

Firstly, the working principle of the absorption chiller experimental platform is explained in this Section. Then, the sixth-order dynamic model based on the absorption refrigeration unit platform is given. Lastly, the proposed algorithm is verified through the sixth-order dynamic model.

\section{A. Single effect absorption chiller experimental platform and data acquisition}

Lithium bromide refrigeration system uses lithium bromide as absorbent, and water as a refrigerant. It evaporates water at high temperature to refrigerate. The unit is mainly composed of generators, evaporators, condensers, absorbers and solution heat exchangers, solution pumps, and so on. Filled with the working pair of lithium bromide solution, the unit has to be ensured to be working in a vacuum state. Schematic diagram of the unit is shown in fig. 5. Diluted lithium bromide solution in the generator is heated by hot water. The water vaporizes into steam, and the concentrated solution goes into the absorber. Evaporated water steam goes into the condenser, which is then cooled by cooling water, and then goes through the throttle. After entering the evaporator, water vaporizes to absorb the heat of chilled water, then the low-temperature water vapor goes into the absorber. Lithium bromide concentrated solution absorbs the vapor and turns into a diluted solution, which goes back to the generator to complete the cycle. The hot concentrated solution passes through the heat exchanger to transfer heat to a diluted solution of lower temperature, thereby relieving the heat load in the generator and absorber. Hot water is the driving heat source. The cooling water continuously removes the heat released from the absorbed refrigerant vapor in the absorber so that the absorber can continuously absorb the water vapor from the evaporator and maintain the internal vacuum of the generator to make the evaporation process to continue. The chilled water of the condenser enters the evaporator through the throttle valve and rapidly expands and evaporates to absorb the chilled water heat in the evaporator. By this, the 
cooling load of the air conditioner is sent to the airconditioned room. The schematic diagram of the single effect absorption chiller is shown in fig. 5 .

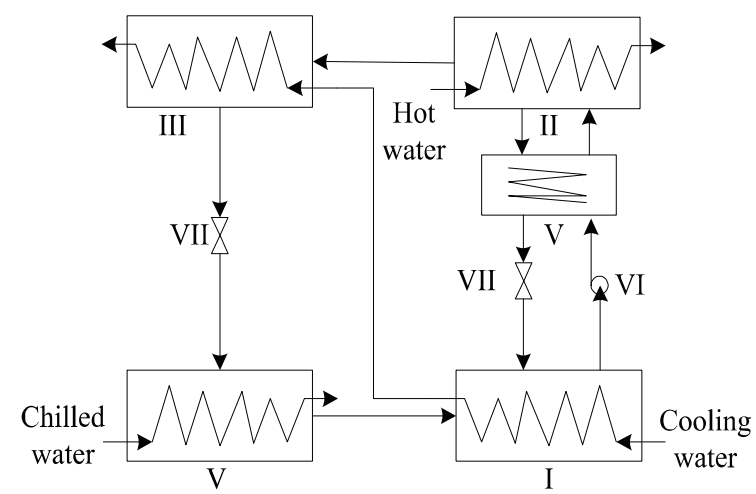

I Absorber II Generator III Condenser IV Evaporator V Solution heat exchangers VI Solution pumps VII Throttle

Fig.5 The schematic diagram of single effect absorption chiller
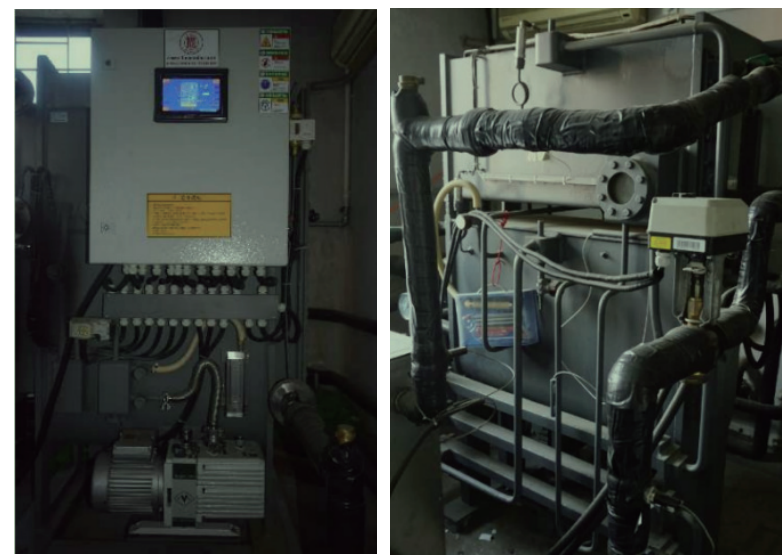

Fig.6 Picture of the single effect absorption chiller experimental platform (left: front, right: back)

Experiments are carried out on Shandong Luxi RXZ11.5 single-effect hot water lithium bromide unit, which is shown in Fig. 6, whose refrigeration power rating is $11.5 \mathrm{~kW}$. Different hot water, chilled water and cooling water temperatures are set, and online operating data has been acquired by changing the frequency of the hot water and chilled water pumps.

The Kingview software is widely used for monitoring and control of industrial processes. Based on the absorption chiller unit, an experimental platform on the upper computer is developed using Kingview, as shown in Fig. 7. During the process of the operating data collection, real-time monitoring information is shown as in Fig. 8.

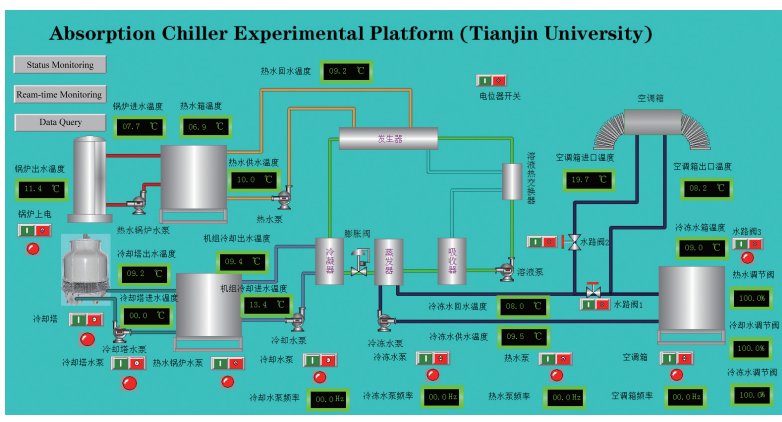

Fig.7 Control flow interface

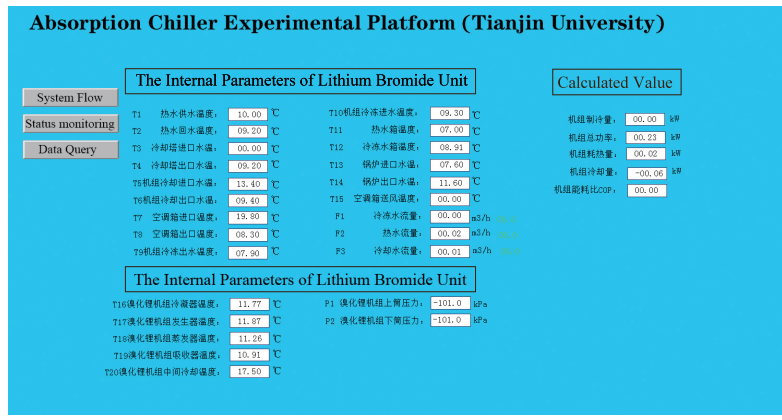

Fig.8 Absorption chiller data collection interface

The experimental platform developed by Kingview automatically records the chilled water outlet temperature curve during the experiment. The sampling time interval is one minute. The ranges of experimental operating data is given in Table 3 .

Table 3 Ranges of experimental operating data

\begin{tabular}{ll}
\hline \hline Variables & Ranges \\
\hline Hot water supply temperature & $58.9-79^{\circ} \mathrm{C}$ \\
Cooling water supply temperature & $21.3-33.6^{\circ} \mathrm{C}$ \\
Chilled water inlet temperature & $5.9-18.3^{\circ} \mathrm{C}$ \\
Hot water flow rate & $2.09-3.48 \mathrm{~m} 3 / \mathrm{h}$ \\
Cooling water flow rate & $4.02-5.35 \mathrm{~m} 3 / \mathrm{h}$ \\
Hot water outlet temperature & $52.2-67.3^{\circ} \mathrm{C}$ \\
Frozen water outlet water temperature & $4.3-19.4^{\circ} \mathrm{C}$ \\
\hline
\end{tabular}

\section{B. Sixth-order dynamic model}

A simplified transient dynamic model for the absorption chiller experimental platform as the working pair is developed in [25], to satisfy the demand for the control system design and optimization. Firstly, the sub-models of each component making up the absorption system are developed based on a series of hypotheses. Considering that the dynamic behaviour of the main components have major influences on the system performance, dynamic modeling methods are used. The remaining components adopt quasi-steady modeling methods or empirical formulas. After that, an initial overall model of the chiller is established by integrating the sub-models. Then, the model is simplified and rewritten in state space form with six state variables. 
Finally, the system model is validated through static comparison between the steady simulation results and the design parameters under the on-design conditions.

The state variables of the overall model of the unit are:

$\mathbf{x}=\left[M_{\text {gen }} X_{\text {gen }} T_{\text {gen }} M_{\text {con }} X_{\text {abs }} T_{\text {abs }}\right]^{T}$.

The state space equation is:

$\mathbf{A}(\mathbf{x}) \dot{\mathbf{x}}=\mathbf{f}(\mathbf{x}, \mathbf{u})$,

where

$\mathbf{A}(\mathbf{x})=\left[\begin{array}{cccccc}a_{11} & 0 & 0 & 0 & 0 & 0 \\ 0 & a_{22} & 0 & 0 & 0 & 0 \\ 0 & a_{32} & a_{33} & 0 & 0 & 0 \\ 0 & 0 & 0 & a_{44} & 0 & 0 \\ 0 & 0 & 0 & 0 & a_{55} & 0 \\ 0 & 0 & 0 & 0 & a_{65} & a_{66}\end{array}\right]$

and

$$
\begin{aligned}
& \mathbf{f}(\mathbf{x}, \mathbf{u})= \\
& {\left[\begin{array}{c}
\dot{m}_{\mathrm{pump}}-\dot{m}_{\mathrm{vl}, 2}-\dot{m}_{\mathrm{con}} \\
\dot{m}_{\mathrm{pump}}\left(X_{\mathrm{abs}}-X_{\mathrm{gen}}\right)+\dot{m}_{\mathrm{con}} X_{\mathrm{gen}} \\
\dot{m}_{\mathrm{pump}}\left(h_{3}-h_{\mathrm{s}, \mathrm{gen}}\right)+\dot{m}_{\mathrm{con}}\left(h_{\mathrm{s}, \mathrm{gen}}-h_{\mathrm{v}, \mathrm{gen}}\right) \\
+\dot{Q}_{\mathrm{gen}} \\
\dot{m}_{\mathrm{con}}-\dot{m}_{\mathrm{vl}, 2} \\
\dot{m}_{\mathrm{vl}, 1}\left(X_{\mathrm{gen}}-X_{\mathrm{abs}}\right)-\dot{m}_{10} X_{\mathrm{abs}} \\
\dot{m}_{\mathrm{vl}, 1}\left(h_{6}-h_{\mathrm{s}, \mathrm{abs}}\right)+\dot{m}_{10}\left(h_{\mathrm{v}, \text { eva }}-h_{\mathrm{s}, \mathrm{abs}}\right)-\dot{Q}_{\mathrm{abs}}
\end{array}\right]}
\end{aligned}
$$

The elements of $A(x)$ are:

$$
\begin{aligned}
& a_{11}=1 \\
& a_{22}=M_{\text {gen }} \\
& a_{32}=\left.M_{\text {gen }} \frac{\partial h_{\mathrm{s}, \text { gen }}}{\partial X_{\text {gen }}}\right|_{T_{\text {gen }}} \\
& a_{33}=\left(M c_{p}\right)_{\text {gen }}+\left.M_{\text {gen }} \frac{\partial h_{\mathrm{s}, \text { gen }}}{\partial T_{\text {gen }}}\right|_{X_{\text {gen }}} \\
& a_{44}=1 \\
& a_{55}=\left(100 M_{\mathrm{LiBr}}-M_{\text {gen }} X_{\text {gen }}\right) / X_{\text {abs }} \\
& a_{65}=\left.\frac{100 M_{\mathrm{LiBr}}-M_{\text {gen }} X_{\text {gen }}}{X_{\text {abs }}} \frac{\partial h_{\mathrm{s}, \text { abs }}}{\partial X_{\mathrm{abs}}}\right|_{T_{\mathrm{abs}}} \\
& a_{66}=\left(M c_{p}\right)_{\mathrm{abs}} \\
& +\left.\frac{100 M_{\mathrm{LiBr}}-M_{\mathrm{gen}} X_{\mathrm{gen}}}{X_{\mathrm{abs}}} \frac{\partial h_{\mathrm{s}, \mathrm{abs}}}{\partial T_{\mathrm{abs}}}\right|_{X_{\mathrm{abs}}} .
\end{aligned}
$$

The meaning of each symbol in the formula is given in Appendix A.

During the simulation and modeling of the absorption refrigeration system, a large number of physical parameters of the lithium bromide solution and refrigerant water need to be calculated. A reasonable design of the physical parameter calculation program is very important for the simulation results. Based on the framework of the sixth-order dynamic model in [25], we finalize the modeling of the single effect absorption chiller experimental platform in our laboratory. The main physical parameters of the refrigerant water involved are: temperature, pressure, saturated refrigerant water vapor specific enthalpy, superheated refrigerant water vapor specific enthalpy, and saturated liquid refrigerant water specific enthalpy. By entering the detailed parameters of the actual absorption chiller experimental platform into the software Refprop, which is launched by the National Institute of Technology (NIST), the physical parameters of the refrigerant water are obtained by the following query statement:

a. Saturation pressure query

$p_{\mathrm{w}}(T)=$

refpropm(' $\mathrm{P}^{\prime},{ }^{\prime} \mathrm{T}^{\prime}, T+273.15,{ }^{\prime} \mathrm{Q}^{\prime}, 0,{ }^{\prime}$ water' $\left.{ }^{\prime}\right)$

b. Enthalpy of saturated liquid water query

$h_{\mathrm{w}}(T)=$

refpropm $\left({ }^{\prime} \mathrm{H}^{\prime},{ }^{\prime} \mathrm{T}^{\prime}, T+273.15,{ }^{\prime} \mathrm{Q}^{\prime}, 0{ }^{\prime}\right.$ water $\left.^{\prime}\right) / 1000$

c. Steam enthalpy of saturated refrigerant query

$h_{\mathrm{v}}(T)=$

refpropm $\left({ }^{\prime} \mathrm{H}^{\prime}, \mathrm{T}^{\prime}, T+273.15,{ }^{\prime} \mathrm{Q}^{\prime}, 1,{ }^{\prime}\right.$ water $\left.^{\prime}\right) / 1000$

d. Enthalpy of superheated steam query

$h_{\mathrm{sv}}(T, p)=$

refpropm $\left({ }^{\prime} \mathrm{H}^{\prime},{ }^{\prime} \mathrm{T}^{\prime}, T+273.15,{ }^{\prime} \mathrm{P}^{\prime}, p,{ }^{\prime}\right.$ water $\left.{ }^{\prime}\right) / 1000$

After completing the modeling of the single effect absorption chiller experimental platform, we have validated its effectiveness through the actual operating data of the unit. The actual operating data is used as the input of the dynamic model for the simulation, and its output is compared with the actual output of the unit. By this validation, the sixth-order dynamic model has been proved to be accurate and effective, and thus it is used for the experiments of the proposed MFACOER approach.

\section{Simulation and analysis}

Through numerical simulation work, the control effect of the improved MFAC-OER method is validated. In this Section, the proposed algorithm is applied to the temperature tracking control of the absorption refrigeration units. The control of water temperature is of great significance to the energy-saving control of absorption refrigeration system. Thus, the temperature of chilled water outlet is often chosen as the manipulated variable.

In this work, we maintain the chilled water outlet temperature stable at the set value by controlling the 
flow of the hot water with the frequency of the hot water pump. Since increasing the hot water inlet temperature can increase the cooling capacity of the absorption chiller, the change in the hot water inlet temperature represents a change in the system load. In our design, the frequency of the hot water pump is the control variable, while the outlet temperature of the hot water inlet temperature represents a change in the system load and is the manipulated variable. The control structure is given in Fig. 9.

The simulation platform is shown in Fig. 10. The simulation platform is mainly composed of two modules, the MFAC-OER method and the sixth-order dynamic model of the unit, which are framed by blue rectangles.

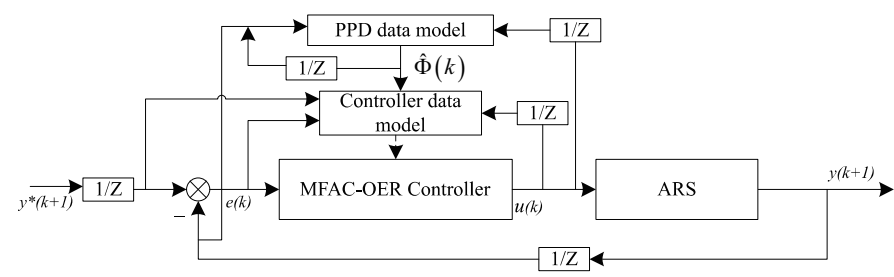

Fig.9 Temperature tracking control system structure

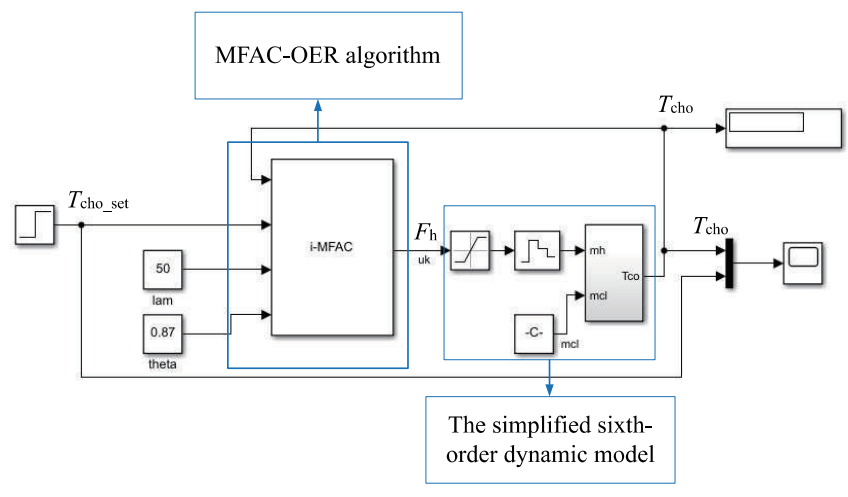

Fig.10 Simulation platform

In Figure 10, the MFAC-OER algorithm module is developed in the Simulink environment of Matlab in this work. The module contains four inputs, namely: chilled water outlet temperature $\left(T_{\text {cho }}\right)$, chilled water outlet temperature setting value $\left(T_{\text {cho_set }}\right), \lambda$, and $\rho$, and one output: hot water pump frequency $\left(F_{h}\right)$. The sixth-order dynamic model: $F_{h}$ represents the hot water pump frequency, $T_{\text {cho }}$ represents the chilled water outlet temperature, and the cooling water pump frequency is set at a fixed value. As can be noticed in Figure 9, the system is in a state of equilibrium at the initial state, $T_{h i}=95^{\circ} \mathrm{C}, T_{c i}=33.1^{\circ} \mathrm{C}, T_{c h i}=14.2^{\circ} \mathrm{C}, F_{c}=$ $35 H Z\left(\dot{V}=2.16 m^{3} / h\right), F_{c h}=23 H Z\left(\dot{V}_{c h}=0.95 m^{3} / h\right)$. We adjust the parameters of the MFAC and the MFACOER to be optimal. Parameters of the MFAC-OER algorithm are fixed as: $\eta=1, \mu=1, \lambda=50$, and $\theta=0.87$. When $k=0$, the system is in equilibrium, and the frozen water outlet water temperature is $7^{\circ} \mathrm{C}$. Set the expected value of the frozen water outlet temperature to be $y^{*}(k)=8^{\circ} \mathrm{C}$. The system response is given in Fig. 11.

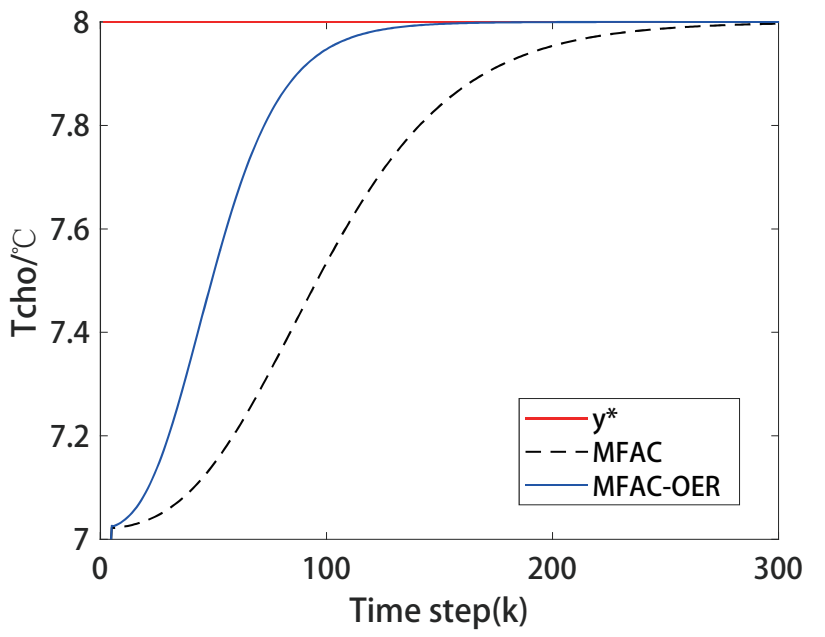

Fig.11 Comparison of step response curve under the same working condition

Table 4 Output correlation performance indicators comparison of MFAC and MFAC-OER

\begin{tabular}{lll}
\hline \hline Control Method & MFAC & MFAC-OER \\
\hline Rise Time $(\mathrm{s})$ & 162.47 & 83.11 \\
Adjustment time $(\mathrm{s})$ & 257.92 & 119.71 \\
Steady-state error $\left({ }^{\circ} \mathrm{C}\right)$ & 0 & 0 \\
MSE & 0.3513 & 0.1877 \\
MAE & 0.6007 & 0.3792 \\
\hline
\end{tabular}

It can be seen from Fig.11 and Table 4 that the MFAC-OER method proposed in this work is superior to the MFAC method with fast tracking characteristics, so as to keep the outlet temperature of the frozen water stable. Detailed analysis are as follows:

a. For the rise time, the MFAC-OER method is nearly half of the MFAC as shown in Table 4.

b. In terms of the adjusting time, the MFAC-OER method is less than half of the MFAC method.

c. These two methods have no steady-state error.

d. The MAE and MSE achieved by the MFAC-OER method are about half of that of the MFAC method, which well illustrates its higher accuracy and better stability.

In order to validate the temperature tracking control effect of MFAC-OER method under changing working conditions, we change the chilled water outlet temperature to $y^{*}(k)=9^{\circ} \mathrm{C}$ at $k=500$, and then observe the corresponding process. The system response curve is given in Fig. 12. 


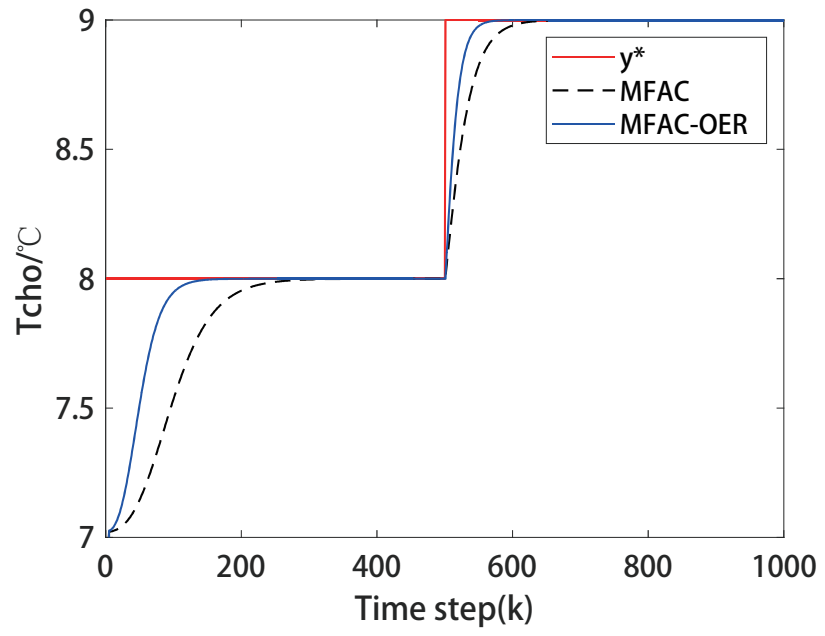

Fig.12 Comparison of step response curve under variable conditions

Table 5 Error comparison of MFAC and MFAC-OER

\begin{tabular}{l|cc}
\hline \hline Control method & MFAC & MFAC-OER \\
\hline MAE & 0.9973 & 0.8144 \\
\hline MSE & 0.5752 & 0.3326 \\
\hline
\end{tabular}

It can be seen from Fig. 12 and Table 5 that in the case of variable working conditions, the MFACOER method can respond to the feedback much faster, thus better tracking the given outlet temperature of the chilled water. As in Table 5, MAE and MSE of the MFAC method are both higher than that of the MFACOER method, which further confirms the effectiveness of the proposed method.

\section{Conclusion}

In this work, a new nonlinear control law, MFAC-OER, based on the MFAC method is developed. We prove the convergence and stability of our new control method. Moreover, a sixth-order dynamic model of the absorption chiller is built, through which, the effectiveness of the proposed control method is validated. Various experiments have been carried out and the results showed that our MFAC-OER method is significantly superior than to the MFAC method under different conditions. The tracking speed is improved by a factor of $2-3$, and it well maintains the fast response characteristics and robustness of the MFAC strategy. The MFAC-OER method proposed in this work is proved to be effective in the temperature tracking control of the absorption chiller through its sixth-order dynamic model. Our next step will use KingView configuration software to further ap- ply the proposed algorithm to the absorption chiller unit.

\section{Funding}

This work is supported by the National Natural Science Foundation of China (Grant No. 61773282, Grant No. 61873181 and Grant No. 61922062).

\section{Compliance with ethical standards}

\section{Conflict of Interest}

The authors declare that they have no conflict of interest.

\section{References}

1. Shin, Y., Seo, J.A., Cho, H.W., et al.: Simulation of dynamics and control of a double-effect $\mathrm{LiBrH} 2 \mathrm{O}$ absorption chiller. Appl. Therm. Eng. 29(13), 2718-27 (2009)

2. Dewar, M.J.S., Harris, J.M.: Stereochemistry of the reactions of secondary cyclopropyl bromides with lithium. J. Am. Chem. Soc. 91(13), 3652-3653 (1969)

3. Didion, D., Radermacher, R.: Part-load performance characteristics of residential absorption chillers and heat pump. Int. J. Refrig. 7(6), 393-398 (1984)

4. Zinet, M., Rulliere, R., Haberschill, P.: A numerical model for the dynamic simulation of a recirculation single-effect absorption chiller. Energy Convers. Manage. 62, 51-63 (2012)

5. Liao, X., Radermacher, R., Absorption chiller crystallization control strategies for integrated cooling heating and power systems. Int. J. Refrig. 30(5), 904-911 (2007)

6. Chow, T.T., Zhang, G.Q., Lin, Z., et al.: Global optimization of absorption chiller system by genetic algorithm and neural network. Energy Build. 34(1), 103-109 (2002)

7. Chang, Y.C., Lin, J.K., Chuang, M.H.: Optimal chiller loading by genetic algorithm for reducing energy consumption. Energy Build. 37(2), 147-155(2005)

8. Hou, Z.S., Wang, Z.: From model-based control to datadriven control: Survey, classification and perspective. Inf. Sci. 235, 3-35 (2003)

9. Kumar, V., Nakra, B.C.: Mittal A P. A Review of Classical and Fuzzy PID Controllers. Int. J. Intell. Control Syst. 16(3), 170-181 (2011)

10. Park, J., Shim, H., Jun, B.S., et al.: A model estimation and multivariable control of an unmanned surface vehicle with two fixed thrusters. In: OCEANS 2010 IEEE Sydney, pp. 15 (2010)

11. Liao, Y.L., Li Y.M., Wang, L.F., et al.: Heading control method and experiments for an unmanned wave glider. J. Cent. South Univ. 24(011), 2504-2512 (2017)

12. Hou, Z.S., Liu, S., Tian, T.: Lazy-Learning-Based DataDriven Model-Free Adaptive Predictive Control for a Class of Discrete-Time Nonlinear Systems. IEEE Trans. Neural Networks Learn. Syst. 28(8), 1-15 (2017)

13. Hou, Z.: Model Free Adaptive Control. In: Theory and Applications. Springer Berlin Heidelberg, China (2013) 
14. Zhu, Y., Hou, Z.: Controller compact form dynamic linearization based model free adaptive control. In: Decision \& Control. IEEE (2012)

15. Hou, Z.: The Parameter Identification, Adaptive Control and Model Free Learning Adaptive Control for Nonlinear Systems. Northeastern University, China (1994)

16. Roohi, M., Zhang, C., Chen, Y.: Adaptive model-free synchronization of different fractional-order neural networks with an application in cryptography. Nonlinear Dyn. 100(3), (2020).

17. Hou, Z., Chi, R., Gao, H.: An Overview of Dynamic Linearization Based Data-driven Control and Applications. IEEE Trans. Ind. Electron. 64(5), 4076-4090 (2017)

18. Zhi, S., Gao, X.F., Wu, L.L., et al: PSO Optimal Control of Model-free Adaptive Control for PVC Polymerization Process. Int. J. Autom. Comput. (2018)

19. Li, H., Ning, X., Li, W.: Implementation of a MFAC based position sensorless drive for high speed BLDC motors with nonideal back EMF. ISA Trans. 67, 348-355 (2016)

20. Hou, Z., Jin, S.: A Novel Data-Driven Control Approach for a Class of Discrete-Time Nonlinear Systems. IEEE Trans. Control Syst. Technol. 19(6), 1549-1558 (2011)

21. Hou, Z., Xiong, S.: On Model Free Adaptive Control and its Stability Analysis. IEEE Trans. Autom. Control. 1(1), 99 (2019)

22. Yan, J.W., Hou, Z.H.: Convergence of MFAC Based Feedback-Feedforward ILC Systems. In: Chinese Control Conference (CCC), pp. 5. IEEE (2008)

23. Wei, Q., Liu, D., Yang, X.: Infinite Horizon Self-Learning Optimal Control of Nonaffine Discrete-Time Nonlinear Systems. IEEE Trans. Neural Networks Learn. Syst. 26(4), 866879 (2015)

24. Chu, Z., Ma, Y., Cui, J.: Adaptive reactionless control strategy via the PSO-ELM algorithm for free-floating space robots during manipulation of unknown objects. Nonlinear Dyn. (2018)

25. Wen, H.T.: Dynamic Modeling and Optimization Control for Single-Effect LiBr-H2O Absorption Refrigeration System. Tianjin University, China (2020)
Table 6 Appendix A

\begin{tabular}{ll}
\hline \hline Symbol & Description \\
\hline$\dot{m}_{\text {pump }}$ & Solution pump fluid mass flow $(\mathrm{kg} / \mathrm{s})$ \\
\hline$\dot{m}_{\mathrm{con}}$ & Condenser fluid mass flow $(\mathrm{kg} / \mathrm{s})$ \\
\hline$\dot{m}_{\mathrm{vl}, 1}$ & Saturated liquid mass flow $(\mathrm{kg} / \mathrm{s})$ \\
\hline$\dot{m}_{\mathrm{vl}, 2}$ & Saturated gaseous mass flow $(\mathrm{kg} / \mathrm{s})$ \\
\hline$\dot{m}_{10}$ & $\begin{array}{l}\text { Mass flow of refrigerant water vapor } \\
\text { (kg/s) }\end{array}$ \\
\hline$h_{3}$ & $\begin{array}{l}\text { Enthalpy of dilute solution at the inlet of } \\
\text { the generator }(\mathrm{kJ} / \mathrm{kg})\end{array}$ \\
\hline$h_{6}$ & $\begin{array}{l}\text { Enthalpy of concentrated solution at the } \\
\text { inlet of the absorber }(\mathrm{kJ} / \mathrm{kg})\end{array}$ \\
\hline$h_{\mathrm{s}, \text { gen }}$ & Enthalpy of generator solution $(\mathrm{kJ} / \mathrm{kg})$ \\
\hline$h_{\mathrm{s}, \text { abs }}$ & Enthalpy of absorber solution $(\mathrm{kJ} / \mathrm{kg})$ \\
\hline$h_{\mathrm{v}, \text { gen }}$ & $\begin{array}{l}\text { Enthalpy of water vapor at the outlet of } \\
\text { the generator }(\mathrm{kJ} / \mathrm{kg})\end{array}$ \\
\hline$h_{\mathrm{v}, \text { eva }}$ & $\begin{array}{l}\text { Evaporator outlet refrigerant water vapor } \\
\text { enthalpy }(\mathrm{kJ} / \mathrm{kg})\end{array}$ \\
\hline$M_{\text {gen }}$ & $\begin{array}{l}\text { Mass of lithium bromide solution in the } \\
\text { generator }(\mathrm{kg})\end{array}$ \\
\hline$X_{\mathrm{gen}}$ & Generator fluid mass fraction \\
\hline$T_{\mathrm{gen}}$ & Generator solution temperature $\left({ }^{\circ} \mathrm{C}\right)$ \\
\hline$M_{\mathrm{con}}$ & $\begin{array}{l}\text { Mass of liquid refrigerant water in con- } \\
\text { denser (kg) }\end{array}$ \\
\hline$X_{\mathrm{abs}}$ & Fluid mass fraction of absorber \\
\hline$T_{\mathrm{abs}}$ & Solution temperature of absorber $\left({ }^{\circ} \mathrm{C}\right)$ \\
\hline$\dot{Q}_{\mathrm{gen}}$ & Heat transfer rate of generator $(\mathrm{kJ} / \mathrm{kg})$ \\
\hline$\dot{Q}_{\mathrm{abs}}$ & Heat transfer rate of absorber $(\mathrm{kJ} / \mathrm{s})$ \\
\hline$M_{\mathrm{LiBr}}$ & $\begin{array}{l}\text { The molar mass of lithium bromide } \\
\text { (g/mol) }\end{array}$ \\
\hline$M_{\mathrm{w}}$ & Molar mass of water $(\mathrm{g} / \mathrm{mol})$ \\
\hline \hline & Heat capacity $(\mathrm{kJ} / \mathrm{K})$ \\
\hline
\end{tabular}

\section{Appendix}


Figures

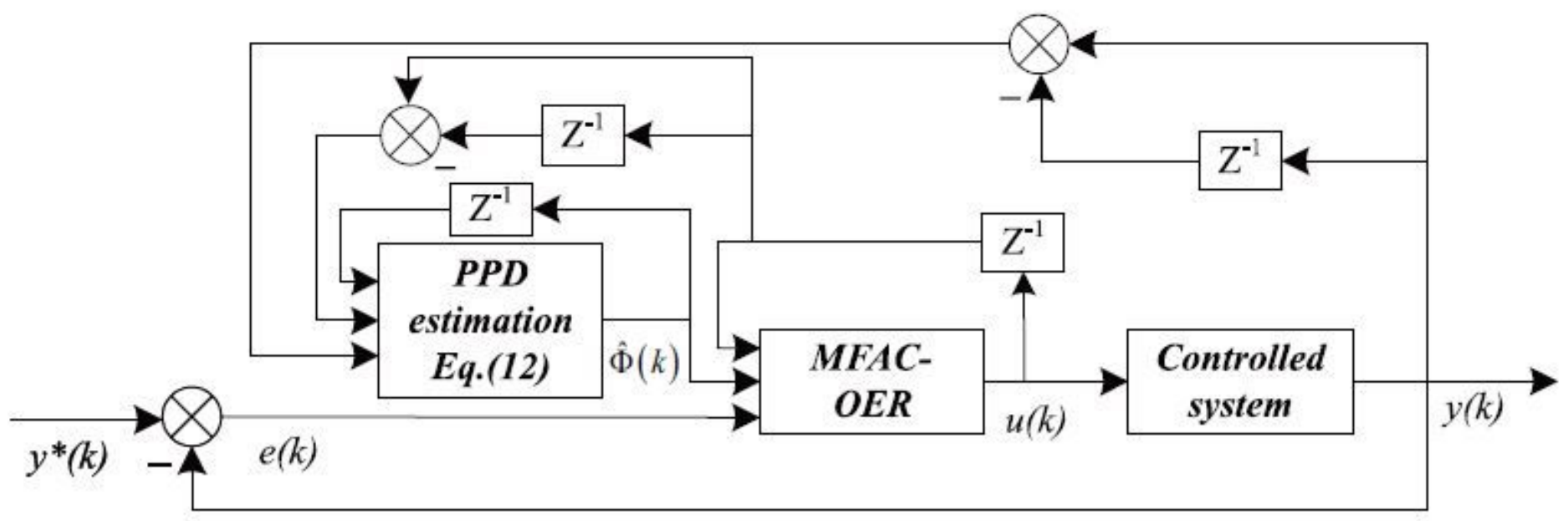

Figure 1

The control block diagram 


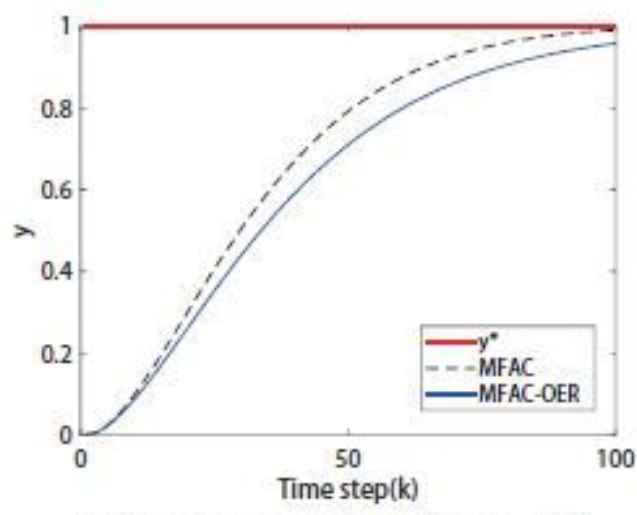

(a) Tracking comparison when $\theta=0.2$

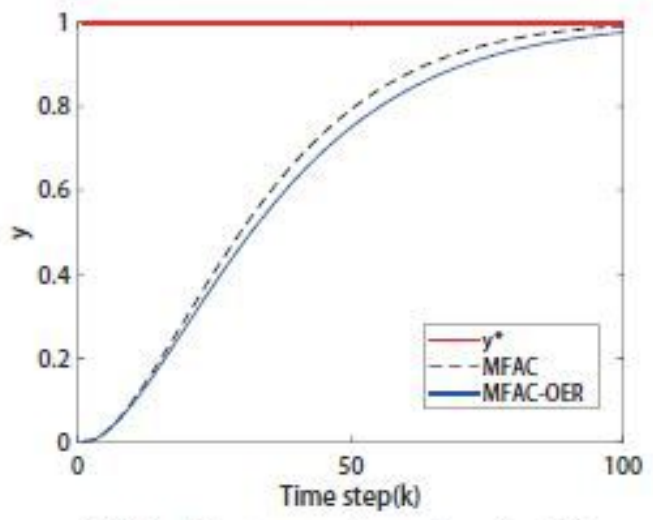

(b) Tracking comparison when $\theta=0.5$

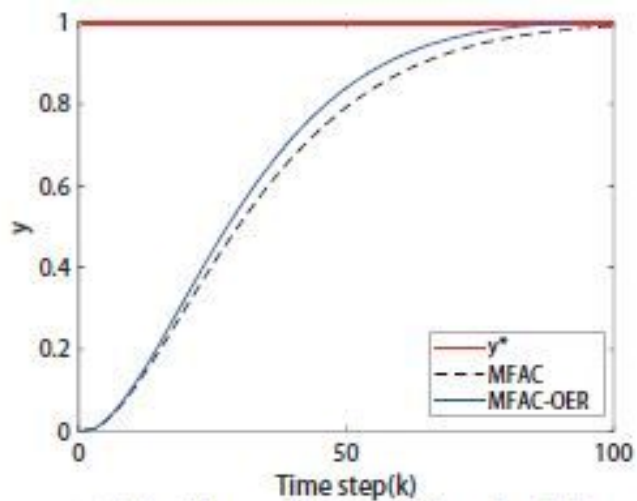

(c) Tracking comparison when $\theta=0.9$

Figure 2

Tracking comparison of $\theta$ under different values 


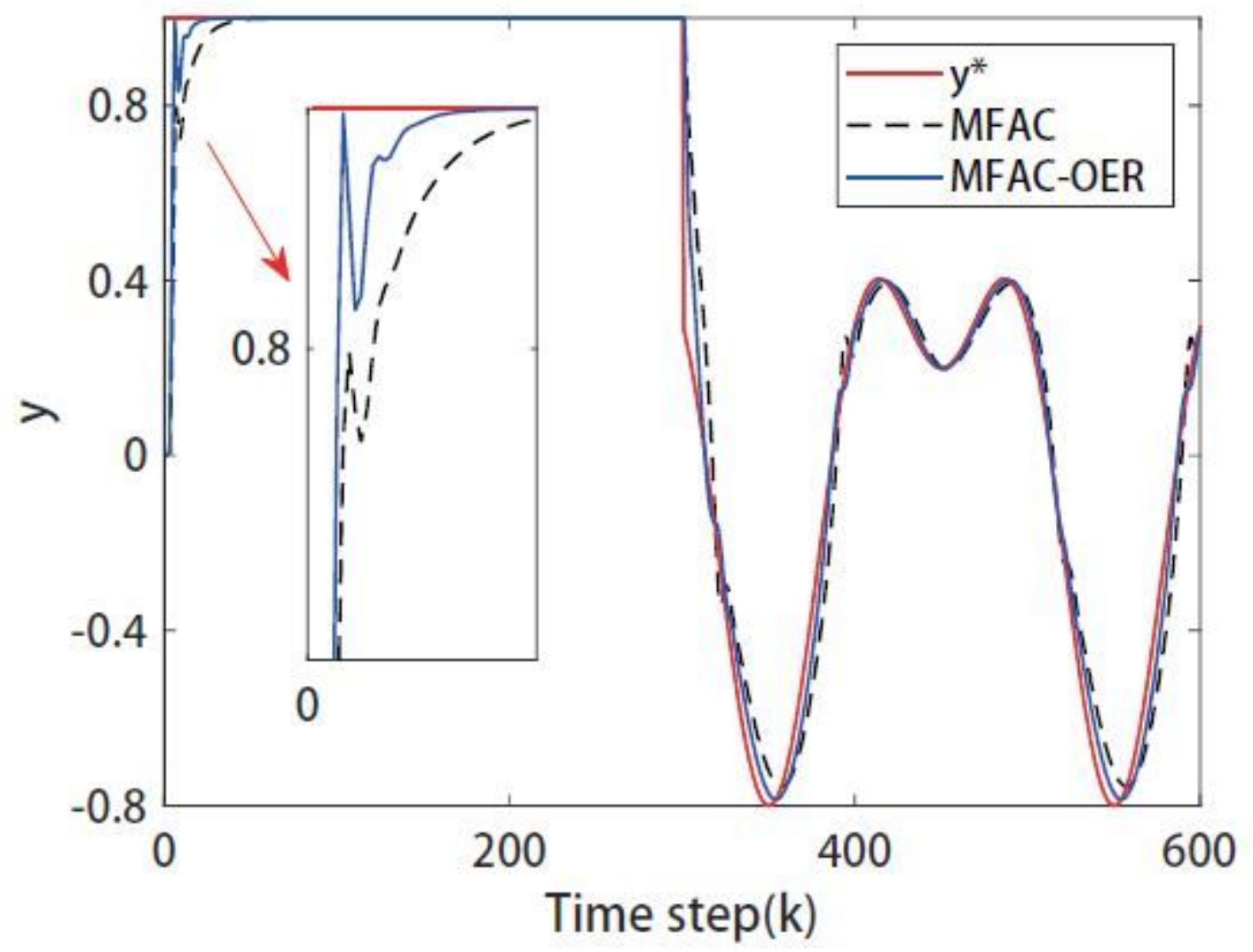

Figure 3

Output comparison 


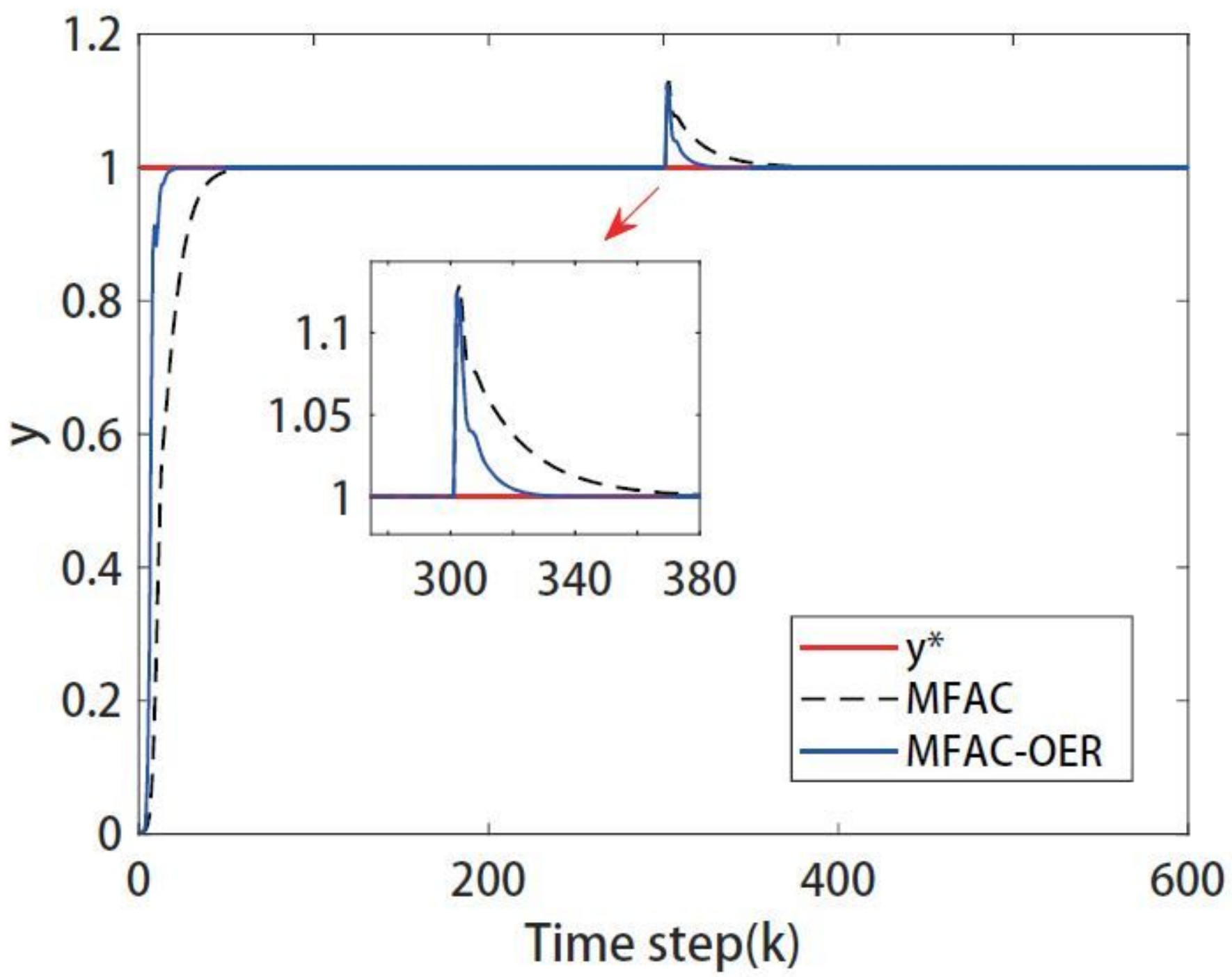

Figure 4

Output comparison 


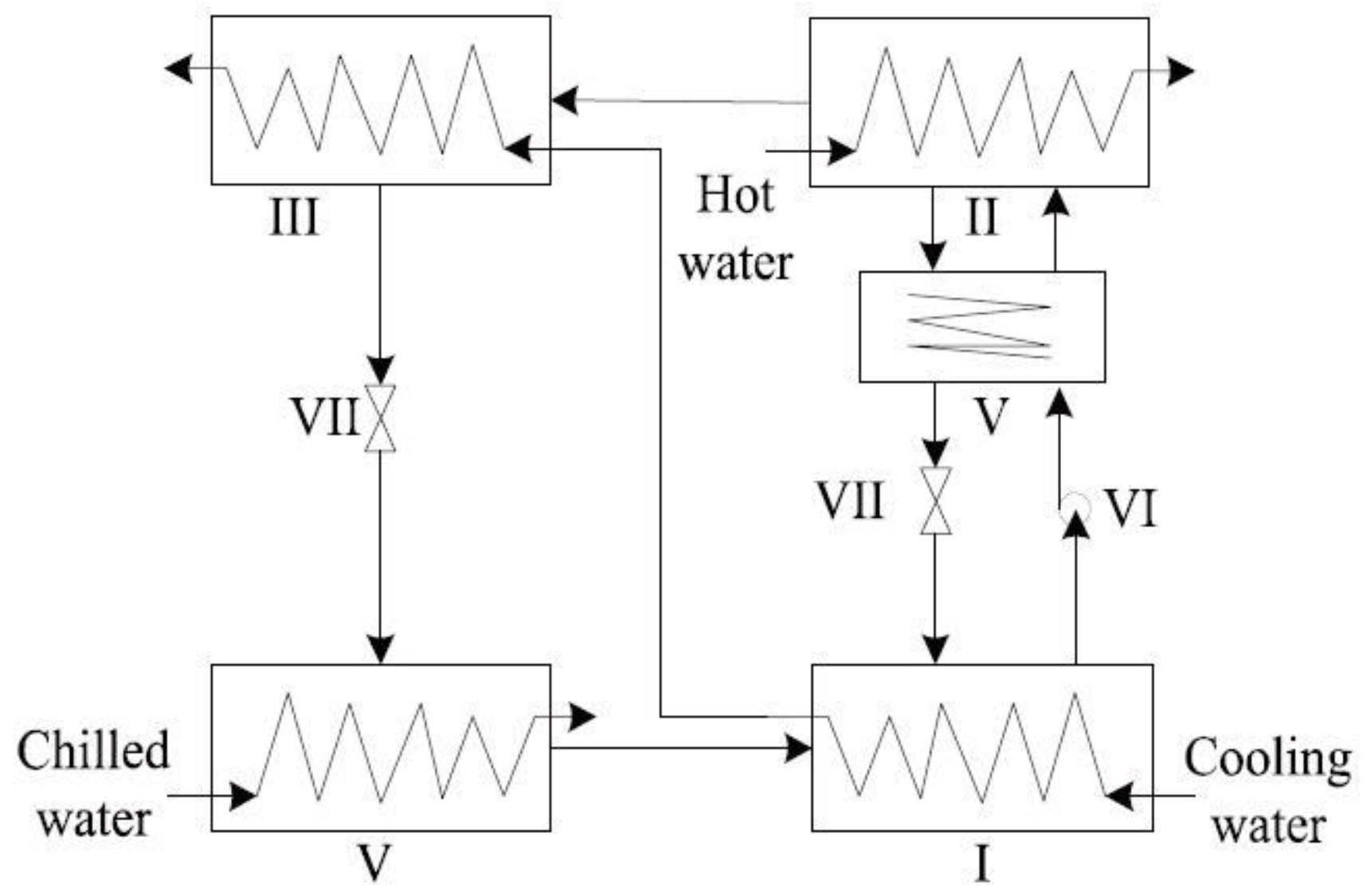

Figure 5

The schematic diagram of single effect absorption chiller 

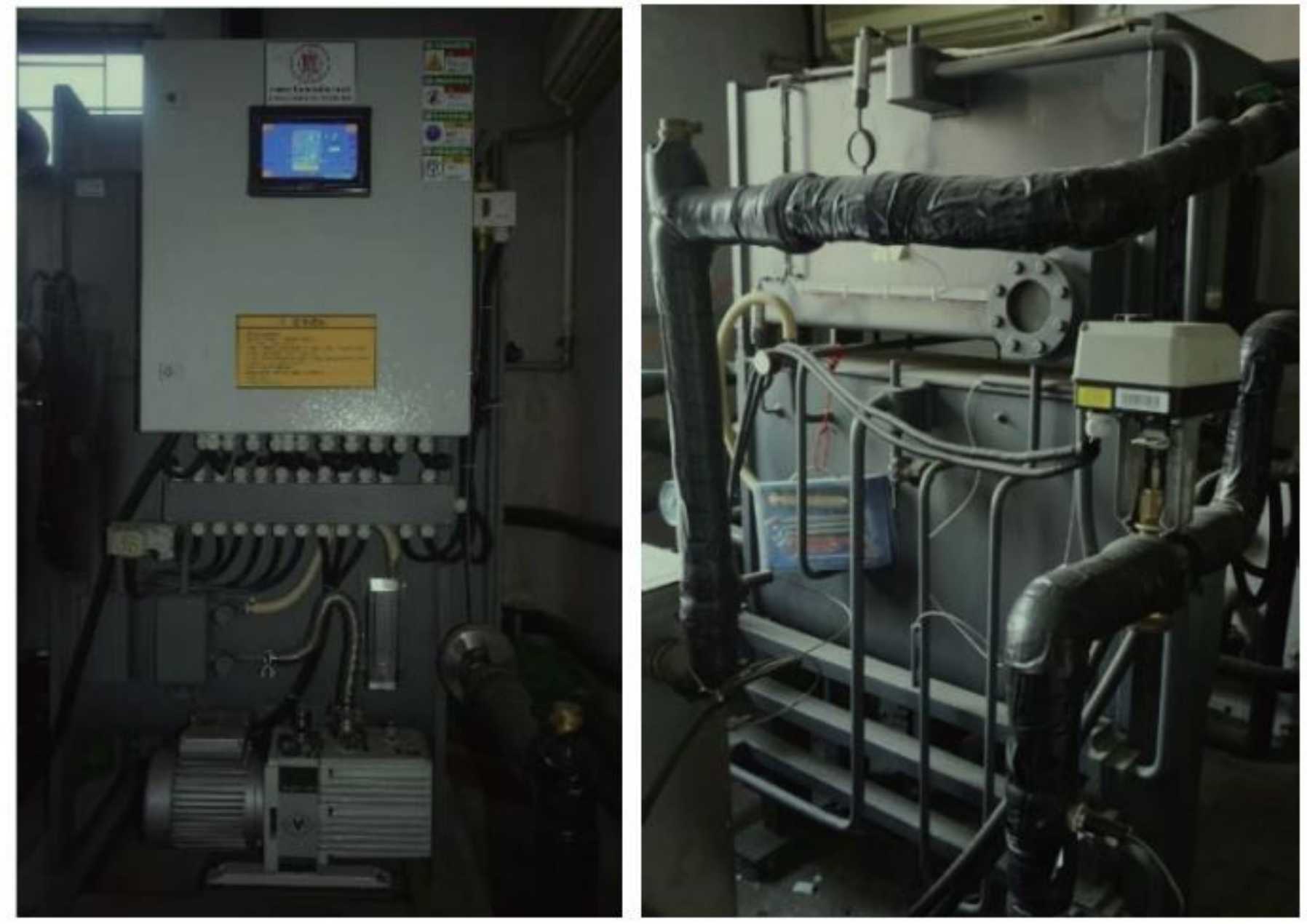

Figure 6

Picture of the single effect absorption chiller experimental platform (left: front, right: back) 


\section{Absorption Chiller Experimental Platform (Tianjin University)}

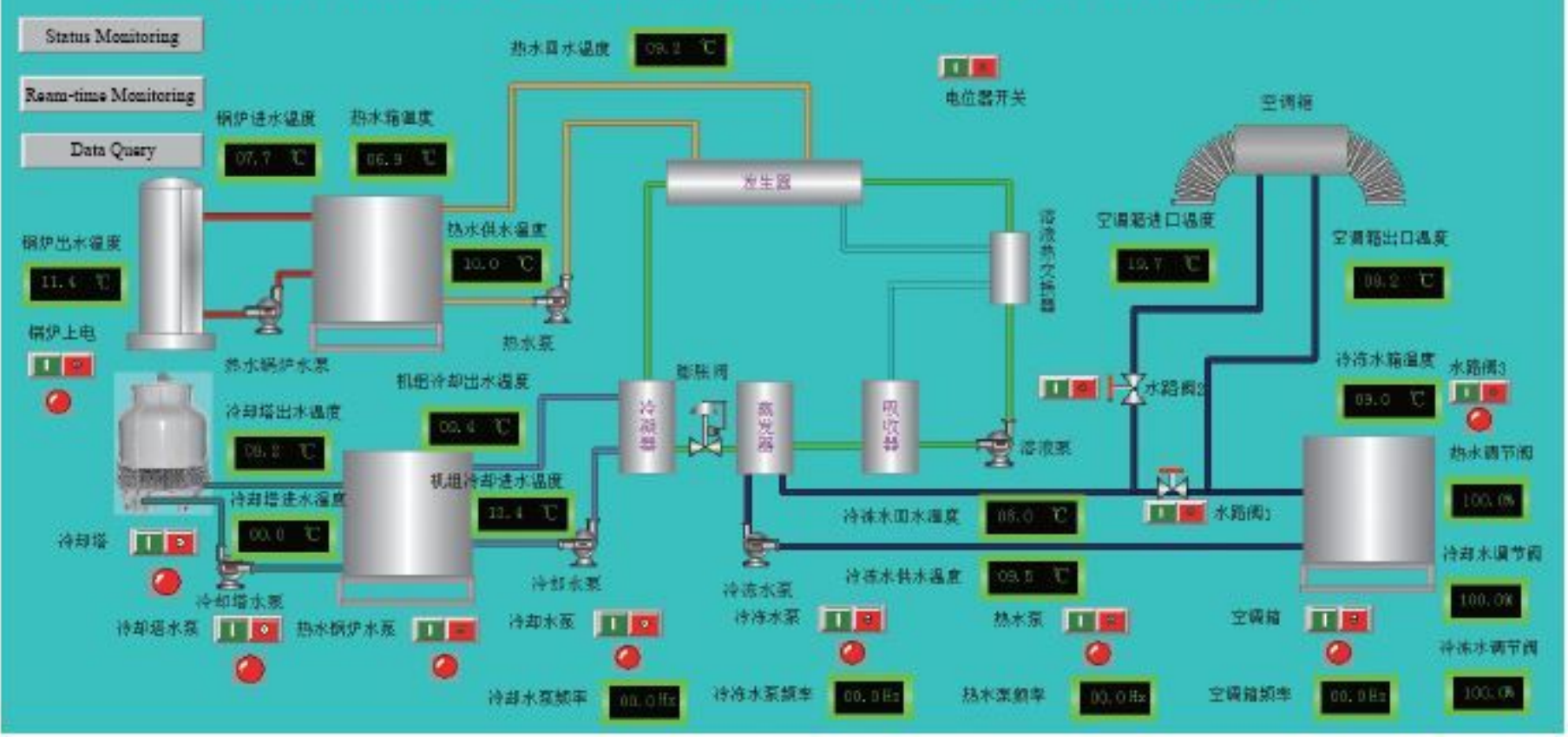

\section{Figure 7}

Control flow interface

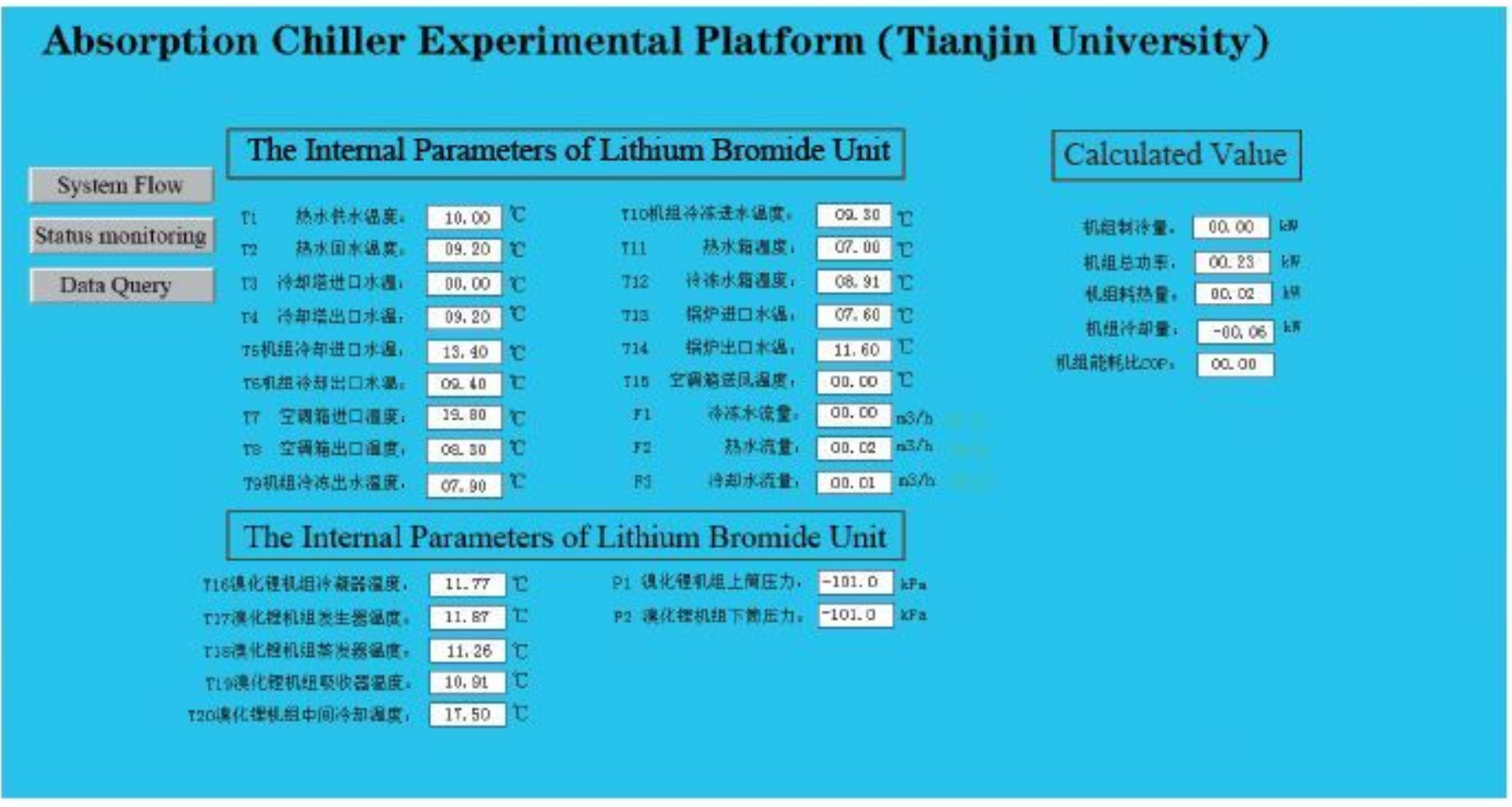

Figure 8

Absorption chiller data collection interface 


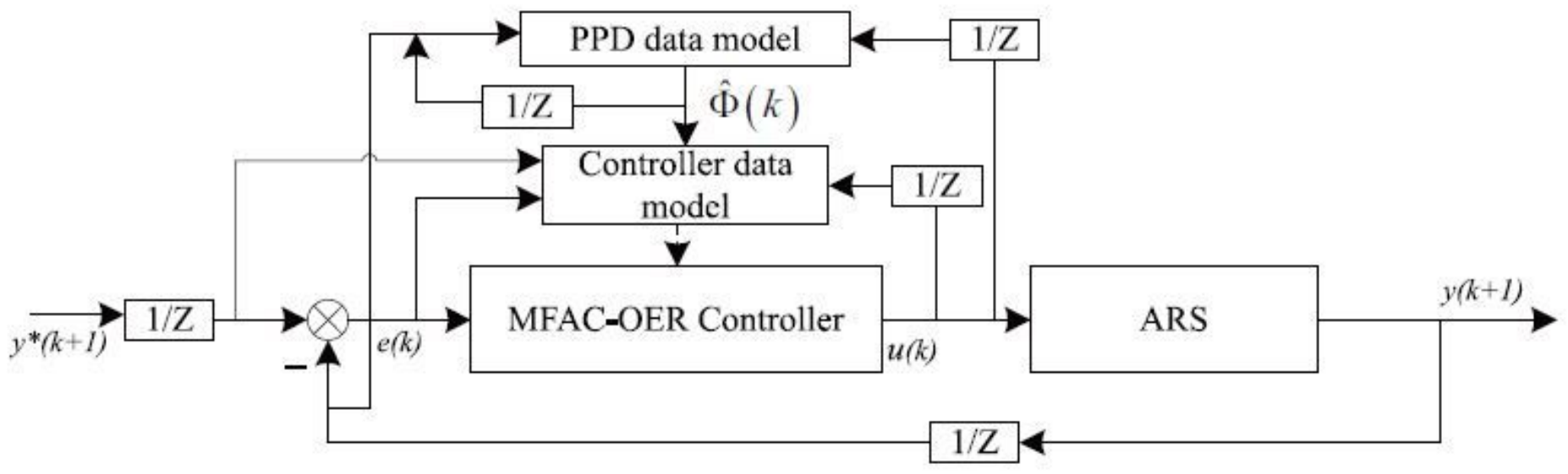

Figure 9

Temperature tracking control system structure

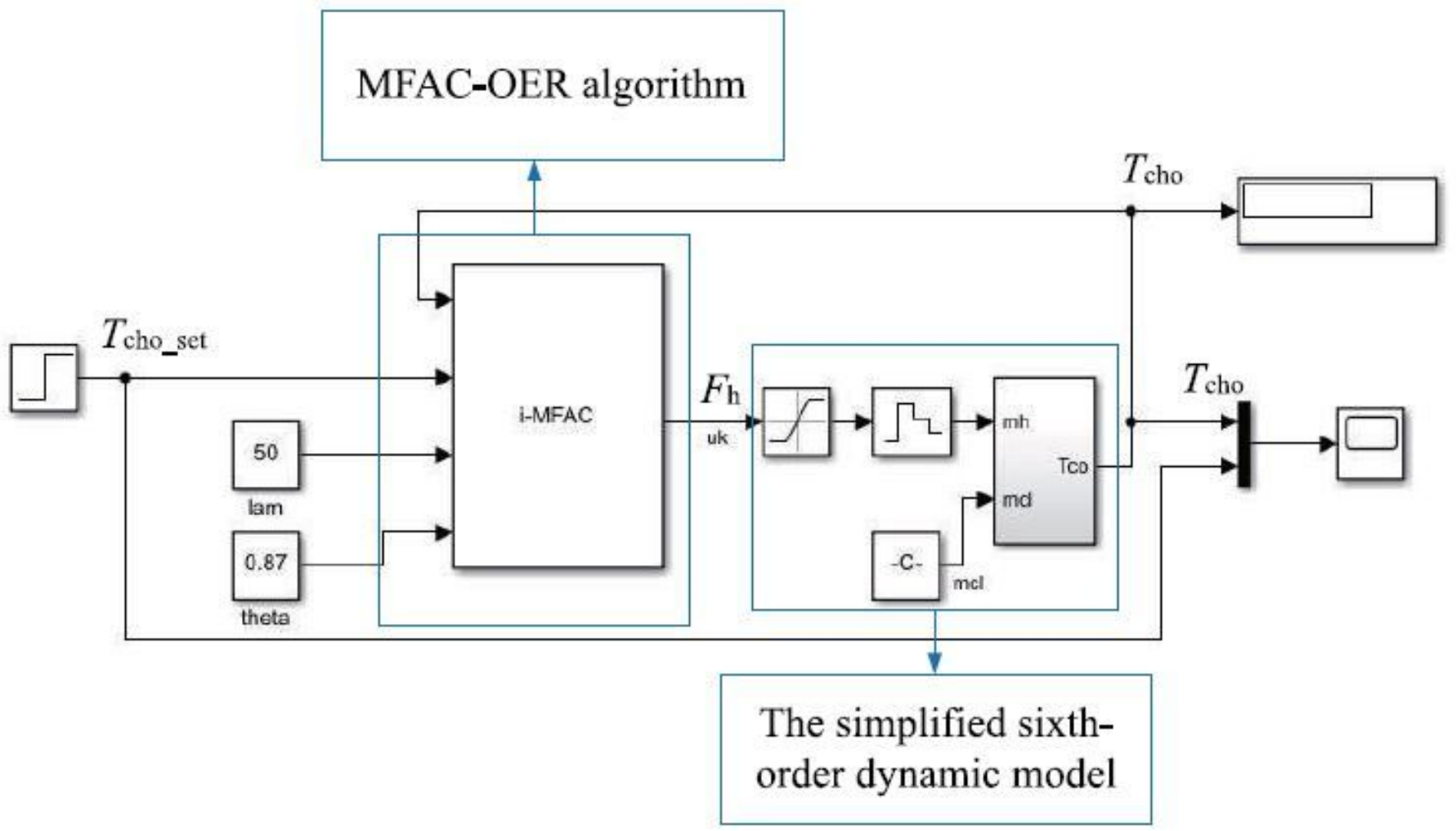

Figure 10

Simulation platform 


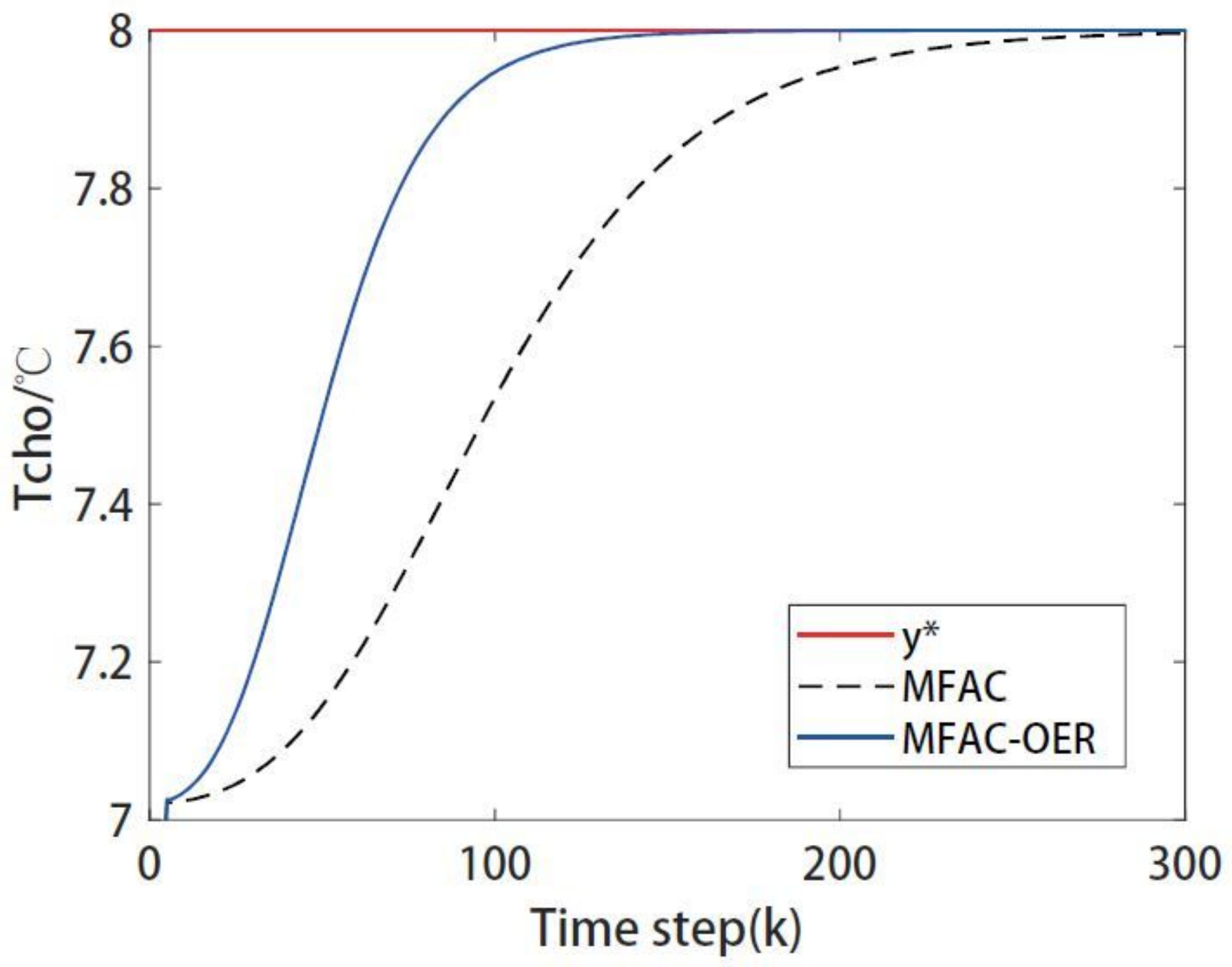

Figure 11

Comparison of step response curve under the same working condition 


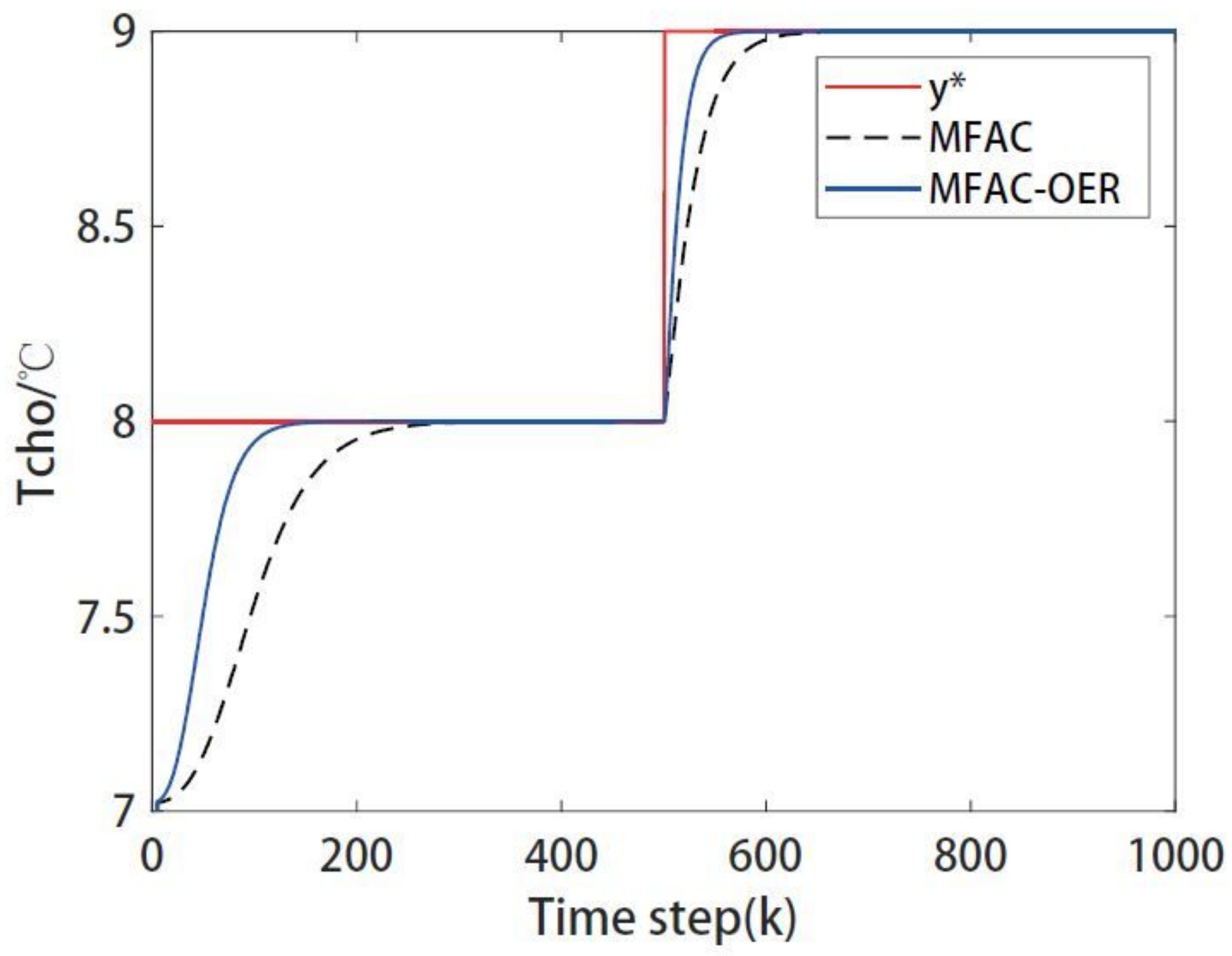

Figure 12

Comparison of step response curve under variable conditions 